\title{
Pulmonary fibrosis: pathogenesis, etiology and regulation
}

\author{
MS Wilson $^{1}$ and TA Wynn ${ }^{1}$
}

\begin{abstract}
Pulmonary fibrosis and architectural remodeling of tissues can severely disrupt lung function, often with fatal consequences. The etiology of pulmonary fibrotic diseases is varied, with an array of triggers including allergens, chemicals, radiation and environmental particles. However, the cause of one of the most common pulmonary fibrotic conditions, idiopathic pulmonary fibrosis (IPF), is still unclear. This review examines common mechanisms of pulmonary wound-healing responses following lung injury, and highlights the pathogenesis of some of the most widespread pulmonary fibrotic diseases. A three phase model of wound repair is reviewed that includes; (1) injury; (2) inflammation; and (3) repair. In most pulmonary fibrotic conditions dysregulation at one or more of these phases has been reported. Chronic inflammation can lead to an imbalance in the production of chemokines, cytokines, growth factors, and disrupt cellular recruitment. These changes coupled with excessive pro-fibrotic IL-13 and/or TGF $\beta 1$ production can turn a wellcontrolled healing response into a pathogenic fibrotic response. Endogenous regulatory mechanisms are discussed including novel areas of therapeutic intervention. Restoring homeostasis to these dysregulated healing responses, or simply neutralizing the key pro-fibrotic mediators may prevent or slow the progression of pulmonary fibrosis.
\end{abstract}

\section{INTRODUCTION}

Following injury it is paramount that tissue architecture is restored to regain normal organ function. Acute inflammatory responses that result from infection or injury can disrupt epithelial and endothelial integrity leading to edema, the recruitment of leukocytes and angiogenesis. The resolution of inflammation through apoptotic and phagocytic pathways often leaves minimal damage and restores normal tissue architecture. However, common to most fibrotic conditions is the presence of a persistent irritant, which can be known agents, such as allergens, toxic chemicals, radiation, or other persistent irritants or unknown factors that trigger idiopathic pulmonary fibrosis (IPF). Indeed, a dysregulated healing response can gradually evolve into a pathogenic fibrotic response when important checkpoints are missed and inflammation becomes unrelenting. These processes can result in a local milieu rich in chemokines, pro-inflammatory, angiogenic, and fibrogenic cytokines, growth factors and tissue destructive enzymes. ${ }^{1-3}$ This mélange of dysregulated processes can result in an increased accumulation of extracellular matrix (ECM) components and fibrotic lesions. Concurrent inflammation, tissue destruction and tissue regeneration can present a "perfect storm" of damage and regeneration.
A tightly regulated repair response following tissue injury is therefore critical. A well-coordinated influx of cells replace resident tissue cells, supply essential nutrients, and reform the tissue during a regenerative period. In some cases, this is followed by a period of fibroplasia, with too much extracellular matrix deposition and connective tissue formation. These events are often associated with vascular diseases and can give rise to many clinical conditions such as atherosclerosis, cirrhosis, scleroderma, asthma, and various types of pulmonary fibrosis. The regenerative process following tissue damage, despite having common mechanisms, can lead to various organ-specific disorders. This review will focus on pulmonary fibrotic conditions and, if known, present common regulatory mechanisms across diseases.

The prevalence and incidence of pulmonary fibrotic diseases are hard to estimate, given the vast array of clinical conditions. IPF affecting 30 in $100000^{4}$ with 34000 new cases annually ${ }^{5}$ and allergic asthma, affecting one in five in the United States; (http://www.cdc.gov/nchs/fastats/asthma.htm) although not always leading to airway remodeling and fibrosis, which are two of the most common pulmonary fibrotic diseases. In addition, there are many other fibrotic diseases of the lung including

\footnotetext{
${ }^{1}$ Immunopathogenesis Section, Laboratory of Parasitic Diseases, National Institute of Allergy and Infectious Diseases, National Institutes of Health, Bethesda 20892 Maryland, USA. Correspondence: MS Wilson (wilsonmar@niaid.nih.gov) 
cystic lung disease, scleroderma, radiation and chemotherapyinduced fibrosis, granulomatous lung disease, sarcoidosis and environmental, and smoking-associated COPD. These fibrotic conditions are frequently fatal, with a median survival time following diagnosis of 3-5 years in the case of IPF. ${ }^{6}$

\section{MECHANISMS OF WOUND HEALING AND FIBROSIS}

A wound-healing response is often described as having three distinct phases-injury, inflammation and repair (Figure 1). Although not all pulmonary fibrotic conditions follow this simple paradigm, it has been a useful model to elucidate the common and divergent mechanisms of pulmonary fibrosis.

\section{Phase I: injury}

Injury caused by autoimmune or allergic reactions, environmental particulates, infection or mechanical damage often results in the disruption of normal tissue architecture, initiating a healing response. Inflammation following insult, can also contribute to cellular damage and tissue destruction. Damaged epithelial and endothelial cells must be replaced to maintain barrier function and integrity and prevent blood loss, respectively. Acute damage to endothelial cells leads to the release of inflammatory mediators and initiation of an anti-fibrinolytic coagulation cascade, ${ }^{7}$ temporarily plugging the damaged vessel with a platelet and fibrin-rich clot. Lung homogenates, epithelial cells or BAL fluid ${ }^{8}$ from IPF patients express greater levels of the platelet-differentiating factor, X-box-binding protein-1, compared with COPD and control patients, ${ }^{9}$ suggesting that clot-forming responses are continuously activated. In addition, thrombin (a serine protease required to convert fibrinogen into fibrin) is also readily detected within the lung and intra-alveolar spaces of several pulmonary fibrotic conditions, ${ }^{10-12}$ further confirming the

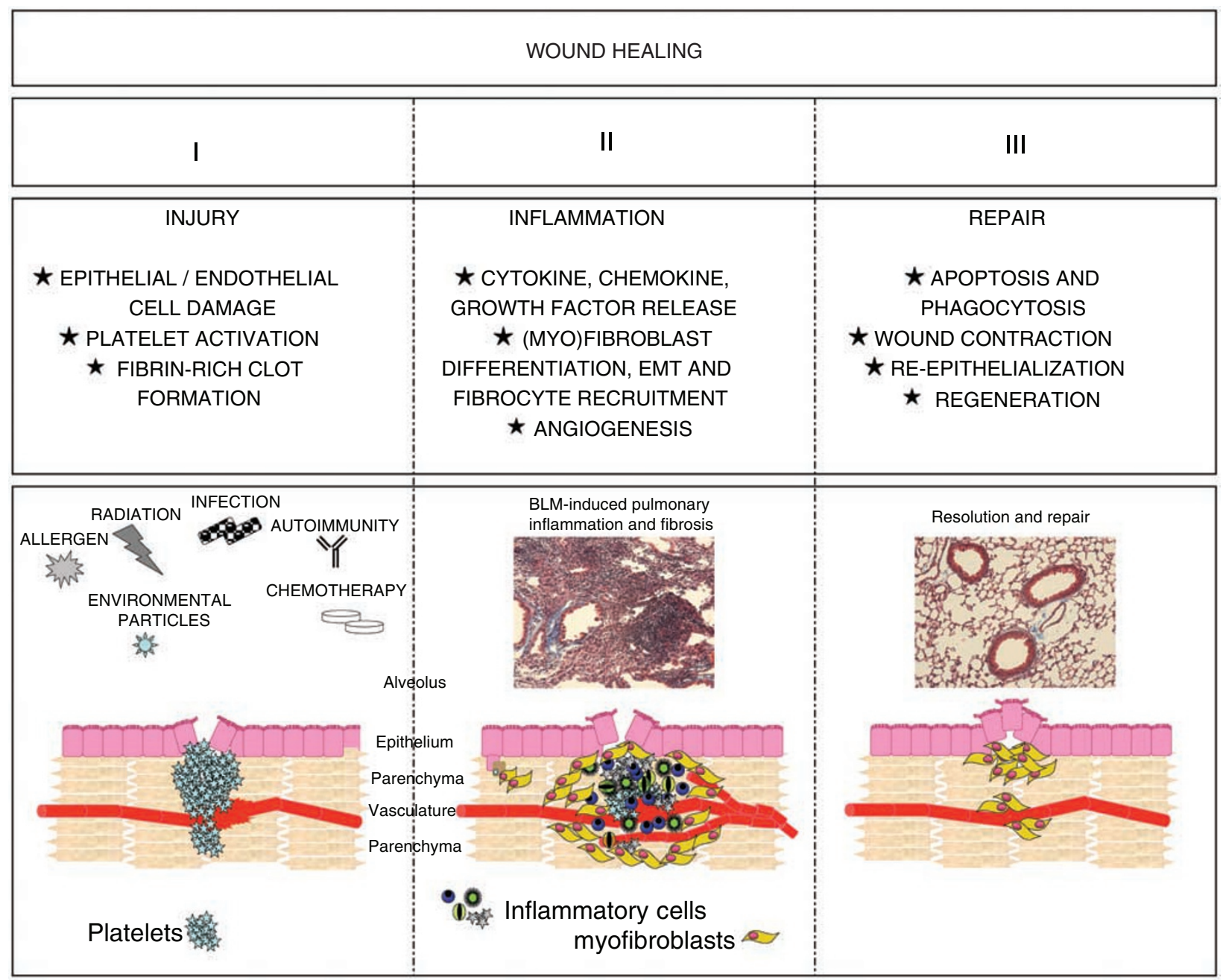

Figure 1 Phases of wound healing. A three-phase injury and wound-healing model describes distinct phases of a successful response. (1) Injury; many agents can cause pulmonary injury, including environmental particles, allergens, infectious agents, chemotherapy and radiation. Disruption of epithelial and endothelial cells initiate an anti-fibrinolytic cascade, temporarily plugging the affected tissue. (2) Inflammation; circulating inflammatory cells and fibrocytes are recruited to the injured site through chemokine gradients, supplying fibroblast-activating cytokines and growth factors. Neovascularization provides access to damaged areas and a steady stream of inflammatory, anti-inflammatory, and phagocytic cells. (3) Fibroblasts contract and decrease the size of the wound. Inflammatory cells and $\alpha$-SMA+ myofibroblasts undergo apoptosis, terminating collagen deposition, and are cleared by phagocytic cells. Epithelial and endothelial cells are replaced and tissue architecture is restored. 
activation of the clotting pathway. Thrombin can also directly activate fibroblasts, ${ }^{13}$ increasing proliferation and promoting fibroblast differentiation into collagen-producing myofibroblasts. ${ }^{14,15}$ Damage to the airway epithelium, specifically alveolar pneumocytes ${ }^{16}$ can evoke a similar anti-fibrinolytic cascade and lead to interstitial edema, areas of acute inflammation and separation of the epithelium from the basement membrane. ${ }^{17}$

Platelet recruitment, degranulation and clot formation rapidly progress into a phase of vasodilation with increased permeability, ${ }^{18}$ allowing the extravasation and direct recruitment of leukocytes to the injured site. The basement membrane, which forms the ECM underlying the epithelium and endothelium of parenchymal tissue, precludes direct access to the damaged tissue. To disrupt this physical barrier, zinc-dependent endopeptidases, also called matrix metalloproteinases (MMPs), cleave one or more ECM constituents allowing extravasation of cells into, and out of, damaged sites. Specifically, MMP-2 (gelatinase A, Type N collagenase) and MMP-9 (Gelatinase B, Type IV collagenase) cleave type $\mathrm{N}$ collagens and gelatin, two important constituents of the basement membrane. ${ }^{19-21}$ In the majority of studies, but not all, ${ }^{22}$ MMP-2 and MMP-9 are upregulated ${ }^{23-26}$ highlighting the tissue destructive and regenerative processes common in fibrotic conditions.

The precise function of MMP-2 and MMP-9 was elegantly demonstrated in a model of allergic airway inflammation and remodeling with $\mathrm{MMP}-2^{-/-}$, MMP-9 $9^{-/-}$and $\mathrm{MMP}^{-2^{-/}} \mathrm{MMP}-$ $9^{-1-}$ double knockout mice. ${ }^{27,28}$ In these studies, the authors demonstrated that MMP-2, and more importantly MMP-9, were required for successful egression and clearance of inflammatory cells out of the inflamed tissue and into the airspaces. In the absence of these MMPs, cells were trapped within the parenchyma of the lung and were not able to move into the airspaces, which resulted in fatal asphyxiation.

The activities of MMPs are controlled by several mechanisms including transcriptional regulation, proenzyme regulation, and specific tissue inhibitors of MMPs. The balance between MMPs and the various inhibitory mechanisms can regulate inflammation and determine the net amount of collagen deposited during the healing response. ${ }^{4}$

\section{Phase II: inflammation}

Once access to the site of tissue damage has been achieved, chemokine gradients recruit inflammatory cells. Neutrophils, eosinophils, ${ }^{29}$ lymphocytes, and macrophages are observed at sites of acute injury with cell debris and areas of necrosis cleared by phagocytes. The influence of specific inflammatory cells on downstream fibrosis, particularly in IPF, is controversial ( ${ }^{30-32}$ and was recently reviewed ${ }^{33}$ ). One school of thought stems from the observation that anti-inflammatory agents have little efficacy in the treatment of IPF ${ }^{34-36}$ and usual interstitial pneumonia patients. Based on these observations, many investigators have suggested that inflammation per se may not be a contributing factor in fibrosis. However, we believe the controversy reflects our limited knowledge and insight into the causative agent(s) and mechanisms involved in IPF. The timing of inflammatory events may determine the role played by the inflammatory process. Early inflammation that is diminished at the later stages of disease may promote wound healing and may contribute to fibrosis. For example the early recruitment of eosinophils, neutrophils, lymphocytes, and macrophages providing inflammatory cytokines and chemokines can contribute to local TGF $\beta$ and IL-13. ${ }^{37-41}$ However, following the initial insult and wave of inflammatory cells, a late-stage recruitment of inflammatory cells may assist in phagocytosis, clear cell debris, and control excessive cellular proliferation, which together may contribute to normal healing. Thus late-stage inflammation may in fact serve an anti-fibrotic role and could be required for successful resolution of wound-healing responses. For example a late-phase inflammatory profile rich in phagocytic macrophages, ${ }^{42}$ assisting in fibroblast clearance, in addition to IL-10-secreting regulatory T cells, suppressing local chemokine production and TGF $\beta,{ }^{43}$ may prevent excessive fibroblast activation. Thus, the absence of inflammation observed in IPF patients, ${ }^{36}$ and interpretation that inflammation is not involved, may simply be a matter of timing. Indeed, corticosteroids that inhibit endogenous suppressive and phagocytic pathways may even be detrimental. However, It should not be forgotten that the mechanisms leading to pulmonary fibrosis are diverse, with immeasurable genetic, environmental and immunological interactions regulating the entire process.

The nature of the insult or causative agent often dictates the character of the ensuing inflammatory response. For example, exogenous stimuli like pathogen-associated molecular patterns (PAMPs) are recognized by pathogen recognition receptors, such as toll-like receptors and NOD-like receptors, and influence the response of innate cells to invading pathogens. ${ }^{44}$ Endogenous danger signal ${ }^{45}$ can also influence local innate cells and orchestrate the inflammatory cascade. For immunologists, classifying the type of immune response into Type-1 (Th1 cells, IFN $\gamma$, TNF $\alpha$, and IgG2 antibody responses, generally considered pro-inflammatory) Type 2 (Th2 cells, IL-4, IL-5, IL-13, and IgE, generally considered as a wound-healing response) and type 17 (Th17 cells, recently associated with pro-inflammatory conditions) based upon the Thelper cell-dominant cytokine responses, although often oversimplifying, allows for easier discussion.

The nature of the inflammatory response dramatically influences resident tissue cells and the ensuing inflammatory cells. Inflammatory cells themselves also propagate further inflammation through the secretion of chemokines, cytokines, and growth factors. Many cytokines are involved throughout a wound-healing and fibrotic response, with specific groups of genes activated in various conditions. For example, chronic allergic airway disease in asthmatics is commonly associated with elevated type-2 cytokine profiles (IL-4, IL-5, IL-13, IL-9, IL-3 ${ }^{46}$ ) whereas IPF patients more frequently present pro-inflammatory cytokine profiles (IL- $1 \alpha$, IL-1 $\beta$, TNF $\alpha$, TGF $\beta$, and platelet-derived growth factors $\left.(\mathrm{PDGF})^{47}\right)$. Among many cytokines in various pulmonary fibrotic conditions, IL-4, IL-13, and TGF- $\beta$ have received significant attention. Each of these cytokines can exhibit significant pro-fibrotic activity, ${ }^{48-51}$ acting through the recruitment, activation and proliferation of fibroblasts, macrophages, and myofibroblasts. ${ }^{2}$ 
Type-2 inflammatory responses: pro-fibrotic IL-4 and IL-13. IL-4, the archetypal type- 2 cytokine, has been firmly established as a pro-fibrotic cytokine and is elevated in IPF, ${ }^{52}$ cryptogenic fibrosing alveolitis, ${ }^{53}$ radiation-induced pneumonitis and pulmonary fibrosis ${ }^{54}$ as well as liver fibrosis following infection with Schistomsoma mansoni. ${ }^{55}$ IL-4 receptors are present on lung fibroblasts ${ }^{49}$ with IL-4 signaling increasing extra cellular matrix proteins and collagen deposition. Surprisingly, some studies have suggested that IL- 4 is superior to TGF- $\beta 1$ at inducing collagen synthesis from fibroblasts. ${ }^{49}$ Indirect mechanisms of IL-4 include its ability to promote the alternative activation of macrophages (AA-Mac), identified by the expression of arginase,${ }^{56}$ Fizz-1, ${ }^{57}$ Ym-1, ${ }^{58}$ and mannose receptors. ${ }^{59}$ Macrophages in general have long been associated with pulmonary fibrosis. However, the precise mechanisms and functions of AA-Macs in pulmonary fibrosis are only now being dissected. AA-Macs can produce TGF- $\beta$, PDGF $^{60}$ and, through arginase upregulation, modulate polyamine and proline biosynthesis, cell growth, and collagen formation. ${ }^{61}$ AA-Macs have been isolated and cultured from the bronchoalveolar lavage (BAL) of IPF patients, ${ }^{62}$ with culture supernatants from these AA-Macs significantly increasing collagen production by normal human fibroblasts in a CCL18-dependent manner. Animal studies have also identified the involvement of AA-Macs in several models of fibrosis, including mice overexpressing human TGF $\beta$ in the lung, ${ }^{63}$ in human and animal studies of dystrophic muscle fibrosis ${ }^{64}$ and in multiple organ fibrosis following infection of IFN $\gamma \mathrm{R}^{-/-}$mice with $\gamma$ herpes virus. ${ }^{65}$ Although not identified as AA-Macs, macrophages in general have long been appreciated in human ${ }^{66}$ and animal models of pulmonary fibrosis. ${ }^{67-69}$ Together these data suggested that direct secretion of TGF $\beta$, PDGF and proline by AA-Macs are just a few of the many ways in which AA-Macs influence the progression of pulmonary fibrosis.

Finally, one of the most renowned properties of IL-4 is its ability to promote the differentiation of T cells into Th2 cells, providing a source of many type- 2 cytokines in this inflammatory axis (IL-5, IL-9, IL-13, and IL-21). The Th2 cytokines interact in dramatic ways propagating wound healing and potentially pro-fibrotic responses. For example, IL-5 mobilizes, matures, and recruits eosinophils, ${ }^{70}$ with IL- 4 promoting TGF- $\beta$ production from eosinophils. ${ }^{37}$ IL- 5 can also augment IL-13 production and increase IL-13-dependent fibrosis. ${ }^{71}$ IL-9 can selectively recruit and activate mast cells, ${ }^{72}$ with mast-cell-derived chymase increasing TGF $\beta$ activity and contributing to pulmonary fibrosis. ${ }^{73}$ Mast cells can also promote fibroblast proliferation, collagen, and MMP production, ${ }^{74}$ and may be involved in subepithelial fibrosis following allergen challenge. ${ }^{75}$ IL-21 can also amplify Th2 pulmonary responses and IL-13-associated fibrosis by upregulating IL-4/IL-13 receptor expression. Mice deficient in the IL-21R showed reduced IL-13-dependent fibrosis following $S$. mansoni infection ${ }^{76}$ and reduced IL-13-mediated AHR in a murine model of asthma, suggesting it may be an important regulator of Th2-driven remodeling in the lung. ${ }^{77}$

IL-13 shares many properties with IL-4, due to common receptor subunits (IL-4R $\alpha$ ), signal transduction pathways and transcription factors (STAT-6). However, recent animal studies have identified IL- $4 \mathrm{R} \alpha{ }_{-}{ }^{78}$ and STAT- $6^{79}$-independent IL-13associated responses, which may involve IL-13 signaling through IL-13R $\alpha 2 .{ }^{80-82}$ Despite the common properties between IL-4 and IL-13, IL-13 has been identified as a key fibrogenic cytokine in many fibrotic conditions $\left({ }^{83}\right.$, reviewed in $\left.{ }^{51}\right)$ and can function independently of TGF- $\beta{ }^{84}$ IL-13 can trigger the differentiation of fibroblasts into $\alpha$-smooth muscle actin ( $\alpha$-SMA) expressing myofibroblasts and PDGF-producing cells ${ }^{85}$ with significant mitogenic properties. Interestingly, IL-13-mediated differentiation of fibroblasts into myofibroblasts is refractory to steroid inhibition, which may explain why steroids are not effective at inhibiting fibrosis.

Pro-fibrotic IL-13 has been widely studied in animal models, where gain of function experiments using a novel transgenic approach (overexpressing IL-13), led to subepithelial fibrosis accompanied by eosinophilic inflammation and mucus production, ${ }^{86}$ comparable to allergen-induced airway responses. Similarly, loss of function studies, blocking or germ line deletion of IL-13 but not IL-4, reduced collagen deposition following exposure to aspergillus, ${ }^{87}$ OVA, ${ }^{88}$ bleomycin ${ }^{89,90}$ and FITC. ${ }^{91}$ It is important to note that the pro-fibrotic properties of IL-13 are not restricted to the lung, because hepatic fibrosis, following infection with Schistomsoma mansoni is also significantly decreased following IL-13 blockade. ${ }^{91}$

In vitro culture of normal human fibroblasts with normal human epithelial cells, which were pre-treated with IL-13, produced significantly more TGF- $\beta$, soluble and fibrillar collagen, ${ }^{92}$ supporting the notion that IL-13 can both directly and indirectly promote collagen production by fibroblasts. Indeed, fibroblasts isolated from IPF patients ${ }^{93}$ and allergic asthmatics ${ }^{94}$ demonstrate a hyper-responsiveness to IL-13, as well as TGF $\beta$ and CCL-2, with significant interplay between these three mediators. ${ }^{93}$ Several animal studies also propose a model where IL-13, through various receptor subunits ${ }^{80,81}$ can induce plasminogen activator and MMP-9, enhancing the release of active TGF $\beta^{95}$ and subsequent fibrosis. Together these human and animal studies indicate a coordinated and potentially combined effect of IL-13 and TGF $\beta$ on fibroblast activation and collagen deposition. ${ }^{40}$

Involvement of TGF $\beta$ in pulmonary fibrosis. TGF $\beta$ is derived from most cell lineages derived from the bone marrow ${ }^{96}$ including T cells, macrophages, ${ }^{97}$ eosinophils, and neutrophils ${ }^{98}$ and is one of the most widely studied pro-fibrotic cytokines. The potent activity of TGF $\beta$ is regulated at the post-transcriptional level by a latency-associated protein (LAP), which keeps TGF $\beta$ in an inactive state. Dissociation of TGF $\beta$ from LAP is achieved by many agents commonly found in fibrotic conditions, including cathepsins, plasmin, ${ }^{99}$ calpain, ${ }^{100}$ thromombospondin, ${ }^{96}$ integrin $\alpha v \beta 6,{ }^{101}$ and MMPs. ${ }^{102}$ These agents trigger the release of biologically active TGF $\beta$. Once active, TGF $\beta$ is incredibly pleiotropic with growth and chemotactic properties, stimulating fibroblast proliferation and the synthesis of extracellular matrix proteins, ${ }^{50}$ recruiting inflammatory cells through MCP-1 (CCL2) ${ }^{103}$ and suppressing T-cell responses. The various and often opposing functions of TGF $\beta$ are likely explained by its various sources and cellular targets. ${ }^{104}$ The inhibitory and 
suppressive properties of TGF $\beta$ were reviewed elsewhere, ${ }^{105-107}$ whereas this review focuses on the pro-fibrotic properties of TGF $\beta$.

Similar to the approach employed to study IL-13-mediated fibrosis in the lung, ${ }^{86}$ active TGF $\beta$ has also been overexpressed in the lungs of mice, with the development of severe interstitial and pleural fibrosis, consisting of excess collagen deposition, extracellular matrix proteins, fibronectin, elastin, and the presence of myofibroblasts. ${ }^{108}$ Interestingly, unlike IL-13 overexpression, TGF $\beta$ did not recruit inflammatory cells or enhance mucus secretion in the lung, suggesting that TGF $\beta$ can directly induce fibrosis in the absence of significant inflammation. Inhibiting TGF $\beta$ activity, by interfering with SMAD-mediated signaling, 109 significantly reduced dermal, ${ }^{110,111}$ renal, ${ }^{112-114}$ ocular, ${ }^{115}$ and pulmonary fibrosis. ${ }^{116,117}$ As mentioned above, TGF $\beta$ independent ${ }^{84,118,119}$ as well as TGF $\beta$ - and IL-13-combined mechanisms can contribute to wound healing and fibrosis. Knowledge of the precise interactions and non-redundant compensatory pathways in addition to disease-specific dominance of IL-13 and/or TGF $\beta$ could significantly improve therapeutic options.

Chemokine cocktails in the fibrotic lung. Cytokine-producing cells are efficiently recruited to sites of injury through chemokine gradients. Many chemokine gradients develop during wound-healing responses, each recruiting specific chemokine receptor-bearing cells; however, the CC and CXC chemokine families have received considerable attention in fibrotic responses. For example, eosinophils bearing CCR3 and following CCL11 (Eotaxin) gradients and neutrophils, macrophages and monocytes, bearing CCR2 and following IL-8 (KC in mice), IL-17, CCL2 (MCP-1) and CCL3 (MIP1 $\alpha$ ) gradients ${ }^{120}$ have all been implicated in pulmonary fibrosis. CCL2, CCL3, and CCL11 are themselves upregulated in pulmonary fibrotic conditions, ${ }^{121-127}$ with gene-deficient animal models confirming their importance. ${ }^{124,128,129}$ However, a previously underappreciated circulating cell, the fibrocyte, expressing CCR2,${ }^{130}$ CCR3, ${ }^{131}$ CCR $5,{ }^{132}$ and CCR7, ${ }^{131}$ as well as CXCR $4,{ }^{133}$ represents a significant population of collagen-producing cells. ${ }^{134}$ The discovery of a rapid, ready, and plentiful supply of collagen-producing fibrocytes from the bone marrow adds a new dimension to pulmonary wound repair and fibrosis. ${ }^{135,136}$ Currently, there are three potential origins of $\alpha-\mathrm{SMA}^{+}$myofibroblasts in lung fibrosis; (1) resident interstitial fibroblasts differentiating into collagen-secreting and extracellular matrix producing cells; (2) a process of epithelial to mesenchymal transformation (EMT) where local epithelial cells adopt fibroblast-like properties and (3) the extravasation of circulating fibrocytes, originating from the bone marrow and differentiating in the tissue into myofibroblasts. ${ }^{137}$

During chronic injury, endothelial cells enter a process of vasculogenesis (de-novo blood vessel formation) and angiogenesis (budding of new capillary branches from existing blood vessels), ${ }^{138}$ laying down dense vascular beds permeating fibrotic and regenerative tissue. Angiogenesis can be controlled by several angiogenic factors including vascular endothelial growth factor (VEGF), fibroblast growth factor, TGF $\beta$, PDGF, angiopoietin 1 (Ang1) and a vast array of cytokines ${ }^{139}$ and chemokines. ${ }^{137}$

In particular, $\mathrm{CXC}$ chemokines identified as angiogenic or angiostatic by their amino terminus, 3-aa sequence (Glu-LeuArg), known as the ELR motif, regulate the degree of neo-vascularization and remodeling. In general $\mathrm{ELR}^{+} \mathrm{CXC}$ chemokines (CXCL1, 2, 3, 5, and 8), which bind to CXCR2, are angiogenic and $\mathrm{ELR}^{-} \mathrm{CXC}$ chemokines (CXCL4, 9, 10, and 11), which bind to CXCR3, are angiostatic. BAL fluid from IPF patients is rich in $\mathrm{ELR}^{+} \mathrm{CXC}$ chemokines with a relative downregulation of ELR ${ }^{-}$CXC chemokines. ${ }^{139-141}$ Imbalanced ELR ${ }^{+}$and $\mathrm{ELR}^{-} \mathrm{CXC}$ chemokine levels have also been observed in animal models of pulmonary fibrosis, ${ }^{142-144}$ confirming observations made in patients.

In summary, inflammation and the recruitment of circulating granulocytes, lymphocytes, monocytes, macrophages, and fibrocytes, presents a continuous supply of pro- and anti-fibrotic players, vital for efficient wound repair but potentially deadly when not adequately controlled. Every step of this pathway requires negative feedback loops that evoke significant control over the entire process. An imbalance in chemokine production coupled with dysregulated cellular recruitment can result in an excess of pro-fibrotic IL-13 or TGF $\beta$, a surplus of myofibroblasts, and can convert a normal wound-healing response into a pathological fibrotic reaction.

\section{Phase III: tissue repair and contraction}

The closing phase of wound healing consists of an orchestrated cellular re-organization guided by a fibrin-rich scaffold formation, wound contraction, closure and re-epithelialization. The vast majority of studies elucidating the processes involved in this phase of wound repair have come from dermal wound studies and in vitro systems. For this reason, we will extrapolate these studies to the lung, where possible.

Myofibroblast-derived collagens and $\alpha$-SMA form the provisional extracellular matrix, with macrophage, platelet, and fibroblast-derived fibronectin ${ }^{145,146}$ forming a fibrin scaffold. Collectively, these structures are commonly referred to as granulation tissues. Primary fibroblasts or alveolar macrophages ${ }^{147}$ isolated from IPF patients produce significantly more fibronectin and $\alpha$-SMA than control fibroblasts, ${ }^{148}$ indicative of a state of heightened fibroblast activation. Interestingly, IPF patients undergoing steroid treatment had similar elevated levels of macrophage-derived fibronectin as IPF patients without treatment. Thus, similar to steroid resistant IL-13-mediated myofibroblast differentiation, ${ }^{85}$ macrophage-derived fibronectin release ${ }^{147}$ also appears to be resistant to steroid treatment, providing another reason why steroid treatment may be ineffective. From animal models, fibronectin ${ }^{149,150}$ appears to be required for the development of pulmonary fibrosis, as mice with a specific deletion of extra type III domain of fibronectin (EDA) developed significantly less fibrosis following bleomycin administration ${ }^{148}$ compared with their wild-type counterparts.

In addition to fibronectin, the provisional extracellular matrix consists of glycoproteins (such as PDGF ${ }^{151}$ ), glycosaminoglycans (such as Hyaluronic acid ${ }^{152}$ ), proteoglycans, ${ }^{153}$ and elastin. ${ }^{154,155}$ 
Growth factor and TGF $\beta$-activated fibroblasts migrate along the extracellular matrix network and repair the wound. Within skin wounds, TGF $\beta$ also induces a contractile response, regulating the orientation of collagen fibers. ${ }^{156}$ Fibroblast to myofibroblast differentiation, as discussed above, also creates stress fibers and the neo-expression of $\alpha$-SMA, ${ }^{157}$ both of which confer the high contractile activity ${ }^{158}$ within myofibroblasts. The attachment of myofibroblasts to the extracellular matrix at specialized sites called the "fibronexus" or "super mature focal adhesions" pull the wound together, reducing the size of the lesion during the contraction phase. ${ }^{159}$ The degree of extracellular matrix laid down and, the quantity of activated myofibroblasts ${ }^{160}$ determines the amount of collagen deposition. To this end, the balance of MMPs to TIMPs ${ }^{161-163}$ and collagens to collagenases vary throughout the response, shifting from pro-synthesis and increased collagen deposition, towards a controlled balance, with no net increase in collagen. For successful wound healing, this balance often occurs when fibroblasts undergo apoptosis, inflammation begins to subside, and granulation tissue recedes, leaving a collagen-rich lesion. The removal of inflammatory cells and especially $\alpha-\mathrm{SMA}^{+}$myofibroblasts is essential to terminate collagen deposition. ${ }^{164}$ Interestingly, in IPF patients, the removal of fibroblasts can be delayed, with cells resistant to apoptotic signals, ${ }^{165-167}$ despite the observation of elevated levels of the apoptosis inductor ${ }^{9}$ and FAS-signaling molecules. ${ }^{164}$ This relative resistance to apoptosis may potentially underlie this fibrotic disease. ${ }^{160,168}$ However, it is important to note that several studies have also observed increased rates of collagen-secreting fibroblast and epithelial cell ${ }^{169}$ apoptosis in IPF ${ }^{170}$ suggesting that yet another balance requires monitoring - that of fibroblast apoptosis and fibroblast proliferation. The signals which initiate fibroblast apoptosis in IPF, are not very well understood with several factors postulated, such as cytokine imbalances, genetic causes, and constitutive anti-apoptotic pathways ${ }^{160,165,170,171}$ similar to some cancerous cells.

From skin studies, re-epithelialization of the wound site reestablishes barrier function and allows encapsulated cellular re-organization. Several in vitro and in vivo ${ }^{172}$ models, using human ${ }^{173}$ or rat ${ }^{174}$ epithelial cells grown over a collagen matrix, or tracheal wounds in vivo, have identified significant stages of cell migration, proliferation, ${ }^{175}$ and cell spreading. Rapid and dynamic motility and proliferation, with epithelial restitution from the edges of the denuded area ${ }^{172,173,176}$ occur within hours of the initial wound. In addition, sliding sheets of epithelial cells can migrate over the injured area ${ }^{177,178}$ assisting wound coverage. Several factors can regulate re-epithelialization with serumderived TGF $\alpha^{174}$ or MMP-7 ${ }^{179,180}$ (which itself is regulated by TIMP-1 ${ }^{181}$ ) appearing to play significant roles.

Collectively, the degree of inflammation, angiogenesis, and amount of extracellular matrix deposition all contribute to the net collagen deposition and ultimately whether a fibrotic lesion develops. Therapeutic intervention, interfering with fibroblast activation, proliferation or apoptosis requires a thorough understanding and appreciation of all of the phases of wound repair. Although these three phases are often presented sequentially, during chronic or repeated injury these processes function in parallel, placing significant demands on regulatory mechanisms.

\section{ETIOLOGY AND PATHOGENESIS OF COMMON PULMONARY FIBROTIC DISEASES}

Alleviating symptoms is the primary concern of patients presenting pulmonary fibrosis. Understanding the etiology of pulmonary fibrosis can provide long-term symptomatic relief and possible reversal of the disease. To this end, there are currently several well-known risk factors associated with pulmonary fibrosis that will be described below. In many cases, animal models have obvious advantages in studying the regulatory mechanisms in pulmonary fibrosis and airway remodeling.

\section{Cystic fibrosis and cystic lung disease}

With regard to etiology, cystic fibrosis (CF) is unique among pulmonary fibrotic conditions and can be attributed to a single gene mutation making it the most common monogenic disease of Caucasians, affecting 1 in 2,500-4,000. ${ }^{182}$

$\mathrm{CF}$ transmembrane conductance regulator (CFTR), ${ }^{183}$ is the genetic "Achilles heal" responsible for the disease. The CFTR protein product is a chloride channel protein found in the membrane of cells lining the lungs, as well as the liver, pancreas, intestines, reproductive tract, and skin. ${ }^{184-186}$ However, the leading cause of mortality in humans with CF is lung disease. ${ }^{184}$ In addition to direct effects of CFTR mutations, resulting in deficient cAMP-mediated chloride secretion across epithelia and dysfunctional mucus regulation, CF patients are prone to progressive pulmonary damage, submucosal inflammation, and increased susceptibility to bacterial infection. ${ }^{187}$ Long-term aerosolized antibiotics may limit bacterial colonization; ${ }^{188-190}$ however, a consequence of chronic infection is recurring lung injury, chronic inflammation, ${ }^{191,192}$ airway remodeling, ${ }^{193}$ and fibrosis. The chronic inflammatory response, in particular the neutrophilic response, is a significant feature driving pathology in CF. Gaggar et al. ${ }^{194}$ recently identified that neutrophil elastase, an enzyme that is significantly elevated in BAL fluid from CF patients, can promote pro-MMP9 and inhibit TIMP1, thereby disrupting the protease/anti-protease balance. ${ }^{194-196}$ In addition, epithelial cell regeneration and repair may also be disrupted, accounting for altered lung physiology in CF. ${ }^{197}$ Several $c \mathrm{ftr}^{-1-}$ mice have been developed with varying degrees of lung disease, identifying CF-modifying genes within different founding lines. ${ }^{198-200}$ The monumental task of developing a mouse that spontaneously develops lung disease was achieved, allowing the pathophysiological dissection of murine CF. $\mathrm{ctr} \mathrm{fr}^{-1-}$ mice develop parenchymal interstitial thickening and fibrosis with granulocyte influx, fibroblast infiltration and the deposition of matrix proteins. ${ }^{199}$ The development of a mouse model of CF has allowed interesting studies addressing anti-inflammatory responses, ${ }^{201}$ the involvement of modifier genes, ${ }^{202,203}$ the impact of bacterial infection ${ }^{204,205}$ and multi-organ complications. ${ }^{206}$

\section{Radiation and chemotherapy-induced lung injury}

Thoracic radiation therapy (RT) is used to treat lung, eosophageal, breast, and lymphoid cancers. However, a common 
dose-limiting complication of RT is the development of pulmonary interstitial injury and inflammation, often referred to as radiation pneumonitis and emergence of fibrotic foci. ${ }^{207-209}$ Multiple mechanisms have been identified in RT-induced fibrosis, including alveolar damage, ${ }^{210}$ increased reactive oxygen species (ROS) and the toxic effects of ROS on parenchymal cells, ${ }^{211,212}$ disruption of proliferation-associated transcription factors, ${ }^{213}$ and the influx of inflammatory cells, such as macrophages and lymphocytes. ${ }^{214,215}$ Furthermore, dysregulated pro-inflammatory and pro-fibrotic cytokines, TGF $\beta$, IL-6, MMPs, ${ }^{216-220}$ and chemokines, ${ }^{221}$ in addition to reduced antiinflammatory cytokines following radiation ${ }^{222}$ can further exacerbate the inflammatory and wound-healing response. Animal models have revealed genetic determinants of RT-induced fibrosis $^{213,223}$ corresponding with similar genotype-related associations in humans. ${ }^{224}$ Collectively, RT of the thoracic region can cause significant damage to radiation-sensitive alveolar regions of the lung invoking a dysregulated inflammatory cascade, rich in pro-inflammatory and pro-fibrotic mediators. Dysregulated chemokines, transcription factors, and anti-inflammatory pathways can further compound this uncontrolled response, leading to pulmonary fibrosis.

Similar to radiation therapy, chemotherapy can cause lung injury with variable consequences depending on dose rate, duration, pre-existing lung disease, and concomitant steroid use. ${ }^{225,226}$ The Streptomyces verticullatus-derived antibiotic, bleomycin (BLM), ${ }^{227}$ is effective against squamous cell carcinomas and skin tumors; ${ }^{228}$ however, like RT, an unfavorable side effect involves inflammatory and fibrotic responses in the lung. BLM-induced inflammation occurs in up to $46 \%$ of patients treated ${ }^{229}$ with complications in the lung and skin due to a lack of the endogenous bleomycin-inactivating enzyme, bleomycin hydrolase, in these tissues. ${ }^{230}$

Our understanding of BLM-induced fibrosis has been assisted by the development of animal models, which reproduce many, but not all, of the characteristics of the human disease. ${ }^{230} \mathrm{BLM}$ can directly cause cell death ${ }^{231}$ and reduce $\mathrm{O}_{2}$ into free radicals, causing DNA breakage. ${ }^{232}$ Depending upon the route of administration, epithelial and endothelial cells are some of the earliest cells affected, ${ }^{233}$ causing a leukocyte-rich inflammatory response. Blockade of this inflammatory response in animal models, with anti-CD11 Ab-inhibiting cellular extravasation, dramatically reduced pulmonary collagen and fibrosis, demonstrating the significant contribution of inflammatory cells on the resulting fibrotic response. ${ }^{234}$ The inflammatory cytokines, TNF $\alpha,{ }^{235}$ IL- $1 \beta,{ }^{236}$ IL- $6^{237}$ and pro-fibrotic TGF $\beta^{238,239}$ are accompanied by FAS-L-expressing cells, leading to more apoptosis. ${ }^{16,240}$ Blockade of TNF $\alpha$, IL-1, FAS-Ligand or TGF $\beta$ can reduce the inflammatory and resultant fibrotic response following BLM administration. ${ }^{235,240-242}$ Thus, TNF $\alpha$, IL-1, IL-6, and TGF $\beta$ are some of the possibly many mediators involved in BLM-induced fibrosis. The BLM model has been used to dissect the involvement of many cytokines in the pulmonary fibrotic response. The involvement of type- 2 cytokines is less clear, with IL-4 and IL-5 playing no significant role, ${ }^{243-245}$ whereas IL-13, either directly ${ }^{90}$ or indirectly through TGF $\beta,{ }^{80,81}$ contributes to the fibrotic response. There is also evidence that Type-1 cytokines are involved, ${ }^{246}$ with fewer inflammatory cells, lung hydroxyproline content, weight loss, and mortality observed in IFN $\gamma^{-1-}$ mice. ${ }^{247}$ Blocking the IFN $\gamma$-promoting cytokine IL-12 or germ line deletion of IL-12 ${ }^{248}$ yielded similar results. ${ }^{248} \mathrm{BLM}$, although invoking a significant inflammatory response, can also promote fibroblast proliferation ${ }^{249}$ and TGF $\beta$ production from endothelial cell $\mathrm{s}^{250}$ directly. Thus, BLM appears to have multiple properties, directly causing cell death and apoptosis, invoking an inflammatory response and promoting fibroblast proliferation and TGF $\beta$ production. For these reasons, the mouse model of BLM-induced fibrosis provides a great tool to dissect the relative contribution of the many pathways, cells, and mediators involved in drug-induced fibrosis.

\section{Asthma and allergic airway inflammation}

The number of individuals suffering from allergic airway inflammation and asthma has seen an unprecedented growth over the past 30 years, particularly within the urban areas of both developed and developing countries. ${ }^{251}$ Allergic asthma is a polygenic disease, ${ }^{252}$ characterized by allergen-specific IgE and IgG1, airway and interstitial eosinophilia, mucus secretion and airway hyper-reactivity. ${ }^{253} \mathrm{Chronic}$ asthma with repeated bouts of allergen exposure and dysregulated inflammation at mucosal surfaces can lead to goblet cell hyperplasia, smooth muscle hypertrophy and hyperplasia, angiogenesis and ultimately subepithelial fibrosis. ${ }^{254-257}$

$\mathrm{CD} 4^{+} \mathrm{Th} 2$ cells orchestrate many aspects of the allergic inflammation, driven by dendritic cell or basophil-derived IL-4 and IL-25. ${ }^{258-263}$ Activation and egression of cytokinesecreting Th2 cells into the interstitium and mucosal surfaces of the lung propagate local cellular influx. More specifically, Th2-derived cytokines, IL-5 and IL-9, mobilize, mature and recruit eosinophils and mast cells ${ }^{70,264,265}$ into the tissue and airspaces, and these cells are typically found in biopsies of asthmatic individuals. TGF $\beta$ is also significantly elevated in human asthmatics ${ }^{41,266-270}$ with the degree of subepithelial fibrosis correlating with a loss of forced expiratory volume $\left(\mathrm{FEV}_{1}\right)$. These observations of increased eosinophils, TGF $\beta$ and subepithelial fibrosis led Flood-page et al. ${ }^{271}$ to study the specific cellular source of TGF $\beta$. Indeed, $86 \%$ of TGF $\beta$ mRNA ${ }^{+}$cells in the bronchial mucosa of asthmatics were eosinophils, distinguishing eosinophils as a significant source of pro-fibrotic TGF $\beta$ in the allergic lung. ${ }^{39}$ Furthermore, several studies have identified correlated collagen deposition with increased numbers of tissue eosinophils and myofibroblasts ${ }^{19,38}$ as well as the expression of submucosal MMP9 and MMP12. ${ }^{272}$

These observations have led to several clinical trials and treatment regimens using anti-IL-5 antibodies to block tissue eosinophilia with few successes. Treatment of allergic asthmatic patients, as well as atopic dermatitis patients, ${ }^{273}$ with anti-IL-5 antibodies (mepolizumab) led to significant reductions in tissue eosinophilia, ${ }^{271,274}$ despite no change in late-phase cutaneous allergic reactions. Most striking was a reduced thickness and density of the extracellular matrix (tenascin, lumican, and procollagen III (COL3A)) following anti-IL-5 treatment, suggesting 
that IL-5-mediated tissue eosinophilia was indeed responsible for ECM deposition. However, despite these encouraging results, the precise role and involvement of eosinophils in human asthma is debated, with many clinical trials of anti-IL-5 mAb reporting little to no clinical improvement. ${ }^{275,276}$

Animal studies, using either IL-5-deficient mice ${ }^{277}$ or eosinophil-ablated mice ${ }^{278,279}$ have supported a significant role for eosinophils, with reduced airway remodeling, including peribronchial fibrosis and smooth muscle thickness, in addition to several other features of allergic asthma following chronic airway exposure. Similarly, blocking TGF $\beta^{280}$ or interfering with TGF $\beta$ signaling ${ }^{281}$ could also significantly attenuate airway remodeling following chronic allergen exposure.

Taken together, animal models have demonstrated a clear role for eosinophils and eosinophil-derived TGF $\beta$ in airway damage and remodeling. Human studies, however, have produced a spectrum of results and require additional studies, with welldefined end points to address the role of IL-5 and eosinophils in the progression and resolution of subepithelial fibrosis in asthmatic airways.

IL-13 may also be a damaging cytokine in allergic individuals. Many of the pathological conditions identified in allergic asthmatics can be traced to IL-13. For example, IL-13 can mediate goblet cell hyperplasia in local epithelia ${ }^{282}$ and increase mucus production ${ }^{92}$ that can block the small airways. ${ }^{283,284} \mathrm{IL}-13$ can also promote epithelial repair, ${ }^{285,286}$ fibroblast growth, ${ }^{85,287}$ $\mathrm{EMT},{ }^{288}$ and collagen deposition. ${ }^{92}$ Beyond the airway epithelium, IL-13 also causes smooth muscle hyperplasia ${ }^{289}$ and subepithelial fibrosis. ${ }^{88}$ Similar to mechanisms proposed using the bleomycin model, IL-13 can synergize with and promote profibrotic TGF $\beta^{290,291}$ eotaxin production, ${ }^{40}$ and TIMP expression. ${ }^{292}$ Thus, within the context of allergic asthma, eosinophils, TGF $\beta$, and IL-13 may all contribute to airway remodeling and pulmonary fibrosis.

\section{Less common pulmonary fibrotic conditions with known etiologies}

Environmental particulates from smoking or occupational exposure can have toxic effects on the mucosal surfaces of the lung. For example, jobs that involve mining or that expose workers to asbestos, metal dusts, or silica dust can cause pulmonary fibrosis. ${ }^{293}$ Agricultural workers can also be affected, ${ }^{293}$ with exposure to organic and inorganic substances, ${ }^{294,295}$ fumes, ${ }^{296}$ or moldy hay ${ }^{297}$ causing allergic inflammation and fibrosis, often referred to as Farmer's Lung. ${ }^{298-300}$ Granulomatous lung disease and sarcoidosis is less common, with a global incidence of $16.5-19 / 100,000 .^{301}$ These diseases are significantly influenced by genetic and environmental factors. To date, the causative agents have not been identified. ${ }^{302}$ An alveolar macrophage gene-transcript profile ${ }^{303}$ that is similar to Mycobacterium tuberculosis infection has led to the hypothesis that bacteria may be involved. However, to date, bacteria have not been isolated from sarcoidosis patients. Chronic inflammation and the development of inflammatory cell-rich pulmonary granulomas, ${ }^{304,305}$ rich in type- 1 cytokines and chemokines ${ }^{122,306-309}$ and $\mathrm{T}$ cells ${ }^{310}$ can dramatically disrupt parenchymal architec- ture, endothelial cells and the alveolar spaces of sarcoidosis patients. Immunohistochemical analysis of human and animal lung biopsies and post-mortem histological sections have identified elevated collagen and fibronectin in granulomas of sarcoidosis patients. ${ }^{305}$ Furthermore, co-expression of pro-fibrotic TGF $\beta$ within the granulomas was also observed in sarcoidosis granulomas. ${ }^{311-313}$ Despite these varying etiologies, recurring lung injury and inflammation ${ }^{314}$ is common to many of these fibrotic conditions, and may broadly underlie the pathogenesis of pulmonary fibrosis.

\section{Idiopathic pulmonary fibrosis}

When all known causes of interstitial lung disease and fibrosis have been ruled out, the condition is referred to as "idiopathic" (of unknown origin) pulmonary fibrosis (IPF). Despite an unknown etiology, there are a number of conditions and risk factors associated with the disease including; smoking, ${ }^{315}$ farming, and occupational hazards ${ }^{316,317}$ and viral, and bacterial infections. ${ }^{318-320}$ Furthermore, in one study, IPF patients had a greater propensity to develop primary lung cancer, compared with non-IPF patients with chronic lung disease or patients without lung disease. ${ }^{321}$ Reports of familial aggregation of IPF also suggest that there may be a genetic component to IPF. ${ }^{322,323}$ As mentioned above, the incidence of IPF in the United States is $30 / 100000^{4}$ and 34000 new cases annually, ${ }^{5}$ with a similar increasing incidence of IPF in the United Kingdom. ${ }^{324}$

IPF is characterized by usual interstitial pneumonitis ${ }^{325}$ and progressive interstitial fibrosis caused by excessive extracellular matrix deposition. Regions of fibroblast and myofibroblast accumulation, specifically between the vascular endothelium and alveolar epithelium disrupt the architecture of the lung, giving a "honeycomb" appearance. ${ }^{321}$ The pathogenesis of IPF has been debated for many years with two different schools of thought. One group suggests an inflammatory stimulus is involved, with recurring inflammation leading to immunopathology, tissue destruction and the propagation of a woundhealing response. ${ }^{32,36,326,327}$ Others suggest a slightly different pathogenic mechanism in which an initial or absent inflammatory stage is quickly followed by an uncontrolled wound-healing response. ${ }^{30,328}$ Central to the argument negating the dominant role of inflammation is the inefficiency of corticosteroids and other anti-inflammatory agents to control IPF $^{34,35}$ despite some reports of enhanced survival. ${ }^{329}$ Furthermore, the ability of epithelial cell-derived TGF $\beta^{330,331}$ to invoke a fibrotic cascade with increased interstitial collagen and fibroblast proliferation in the absence of inflammation further support these views. We believe the controversy reflects our limited knowledge and insight into the causative agent(s) and pathogenesis of IPF. A common, and accepted view is the early role of inflammatory events, initiating a wound-healing response. Whether the dysregulated wound-healing response continues in the absence of subsequent inflammation or not has yet to be clarified. Continuous chemokine and cytokine production ${ }^{47}$ in diagnosed IPF patients indicates that damage and subsequent inflammation may be ongoing. 
The cytokine profile from biopsy or BAL-derived cells or BAL fluid of IPF patients is rich in pro-inflammatory cytokines; IL- $1 \beta,{ }^{332,333}$ IL- $8,{ }^{122}$ IL- $18,{ }^{334}$ TNF $\alpha,{ }^{335}$ MCP$1^{122,336}$ as well as Type- 2 cytokines, and their receptors. ${ }^{337,338}$ The mixed cytokine profile, derived primarily from inflammatory cells ${ }^{67}$ and leukocytes, ${ }^{33,339}$ can have significant effects on all aspects of wound healing including vascular remodeling, myofibroblast differentiation, EMT, TGF $\beta$, and IL-13 production. In addition to the direct fibroblast-activating properties of TGF $\beta$ and IL-13, co-expression of these two cytokines in IPF has been observed ${ }^{93}$ Fibroblast hyperplasia ${ }^{170}$ and the reduced expression of apoptotic mechanisms (bcl-2 and membrane FAS-L) ${ }^{340}$ in IPF can further augment the fibrotic response. Collectively, a cascade of failed regulatory mechanisms and hyper-secretion of cytokines, chemokines and growth factors, ${ }^{47}$ culminates in an out-of-control fibroblast-mediated wound-healing response. Physiologically, IPF can dramatically compromise oxygen diffusion, lung function ${ }^{341}$ and is typically a fatal disease.

\section{REGULATION OF PULMONARY FIBROSIS}

It is becoming clear that an imbalance of stimulatory cytokines, chemokines, and growth factors likely over-activate resident parenchymal and circulating cells and may underlie the over exuberant wound-healing responses that lead to fibrosis. In a normally controlled cellular response, negative feed back loops, anti-inflammatory molecules, inhibitory receptors, and apoptotic pathways operate to fine tune and terminate responses once a desired outcome is achieved. Common to many pulmonary fibrotic conditions with both known and unknown etiologies may be a break down in these regulatory mechanisms, resulting in an excessive inflammatory cascade, neo-vascularization, uncontrolled fibroblast activation, and fibrosis. In this section of the review we will highlight some of these endogenous regulatory mechanisms that either operate endogenously or can be exploited therapeutically to counter balance the uncontrolled responses.

\section{Regulation of inflammatory responses: Tregs and IL-10}

$\mathrm{T}$ cells with the primary function of attenuating immune cell activation and proliferation are frequently referred to as regulatory T cells (Treg). Although the specific details of antigen specificity, precise mechanisms of suppression, and distinguishing features continue to grow, their role in fibrotic responses have been under studied. However, given their ability to dampen inflammatory responses, the ability of Tregs to interfere with upstream events and slow the progression of fibrosis has been implied. In particular Treg-derived IL-10, and other surface molecules $^{342}$ although not exclusively derived from Tregs, can function as a general immunosuppressant ${ }^{343}$ and control fibrosis. ${ }^{342}$ Polymorphisms in the signal sequence of the IL-10 gene have been identified in IPF patients, corresponding to reduced IL-10 production, suggesting that endogenous anti-inflammatory mechanisms may be impaired in this condition. Supporting this notion, loss of function studies using LPS-induced lung injury and fibrosis in IL-10-deficient mice led to significantly stronger inflammatory responses with greater subepithelial thickening and extracelular matrix protein content. ${ }^{344}$ In gain of function studies, induction of IL-10 significantly reduced collagen deposition following bleomycin administration in murine models. ${ }^{345}$ Following IL-10 gene delivery BAL fluid TNF $\alpha$ and neutrophil-derived MPO levels were significantly reduced, with another similar study observing reduced macrophage-derived TGF $\beta,{ }^{43}$ suggesting that IL-10 inhibits inflammatory cell recruitment. ${ }^{345}$ Corroborating these findings, Dosanjh et al. ${ }^{346}$ reported higher levels of IL-8, with reduced IL-10 levels in the BAL fluid of cystic fibrosis patients. Thus, IL-10 can attenuate the inflammatory events upstream of the fibrotic pathway. In addition to suppressing inflammatory events, IL-10 can act directly on fibroblasts, reducing TGF $\beta$-induced collagen production. ${ }^{345}$ Following lung injury in a rat model of radiation-induced fibrosis, pneumocytes in the epithelial layer of the lung had reduced expression of IL-10, compared to control lungs, which may permit greater local inflammation. ${ }^{222}$ Thus, IL-10 immunotherapy, with a sound understanding of timing and when to dampen inflammatory events may hold promise for pulmonary fibrotic conditions. ${ }^{347}$ Beyond the lung, IL-10 has been shown to regulate kidney ${ }^{348}$ and liver ${ }^{349}$ inflammation, and fibrosis. ${ }^{350}$ Therapeutically manipulating IL-10, in particular endogenous IL-10-producing cells which may be present but in too low frequencies to significantly halt the inflammatory onslaught, may be a useful avenue to pursue. This has been demonstrated successfully in models of allergic airway inflammation, where a reduction in airway and tissue inflammation, mucus production, and airway hyper-responsiveness was observed. ${ }^{351}$

\section{IL-13R $\alpha 2$ and LAP: endogenous attenuators of fibrosis}

As discussed throughout this review, TGF $\beta$ and IL-13 $3^{51,84,85,352,353}$ are dominant pro-fibrotic cytokines, activating fibroblasts, and promoting differentiation into $\alpha$-SMAproducing myofibroblasts and collagen production. Thus, tight regulation and fine-tuning of these two potent molecules is essential. Two molecules that can serve this very purpose are the IL-13R $\alpha 2$, an endogenous decoy receptor that attenuates IL-13 activity and, as discussed earlier, LAP, a latency-associated protein, which keeps TGF $\beta$ in an inactive state. To our knowledge there are no studies to date reporting the specific induction of endogenous LAP to attenuate TGF $\beta$ bioactivity; however, introduction of exogenous recombinant LAP could theoretically be used to attenuate TGF $\beta$ activity ${ }^{354}$ (similar to anti-TGF $\beta$ antibody ${ }^{280}$ ). Upregulation of a TGF $\beta$-binding protein, endoglin, however has been observed in animal models of renal fibrosis. ${ }^{355}$ Exploiting this pathway to attenuate TGF $\beta$ may be another option. Although the exact mechanism is unknown, the introduction of taurine and niacin into the diet of small rodents attenuates BLM-induced fibrosis, apparently by reducing TGF $\beta$ production, ${ }^{356}$ suggesting that dietary supplements may be useful therapeutics. Disrupting TGF $\beta$-associated ROS ${ }^{357}$ or other downstream TGF $\beta$-signaling pathways ${ }^{358}$ also hold promise.

IL-13R $\alpha 2$ is expressed predominantly by non-hematopoietic cells (unpublished observations) and attenuates IL-13 activity 
in vivo. ${ }^{359}$ Given that IL-13 can act at multiple stages of the inflammatory and wound-healing response, ${ }^{51,92,284,288,358,360}$ it comes as little surprise that attenuation of IL-13 can have profound effects on the degree of pulmonary inflammation and fibrosis in many pulmonary disease models. ${ }^{88,90,361}$ Several methods of IL-13 attenuation have been described, including neutralizing Abs, ${ }^{87}$ treatment with sIL-13R $\alpha 2,{ }^{359,362-364}$ or targeting the IL-13R $\alpha 2$-expressing cells. The conclusions from all of these studies indicate that targeting the IL-13 pathway holds great promise for the treatment of fibrosis.

\section{Resetting the imbalance}

An imbalance of cytokines, chemokines or cells can disrupt many downstream processes (Figure 2). For example, an imbalance between collagen-catabolizing MMPs and their specific inhibitors, TIMPs, can result in excessive collagen breakdown. However, they can also promote TGF $\beta$ activation in peripheral cells. ${ }^{365-367}$ Increased TGF $\beta$ can further feed back to induce more MMPs ${ }^{368}$ and promote EMT. ${ }^{368}$ Thus, a breakdown in one process (MMP production) can quickly catalyze and disrupt other regulatory mechanisms (TGF $\beta$ responses). Within mammalian systems, a refined balance between "on" and "off" signals is critical to maintain homeostasis. In a dysregulated wound-healing response several key mechanisms appear to be off balance (Figure 2).

(1) Inflammation "vs." Immunosuppression. Excessive or recurring inflammatory events can cause excessive wound-healing responses that lead to the development of fibrosis. Either eliminating the causative agent, such as allergen avoidance, or treatments with anti-inflammatory agents such as corticosteroids may help restore the balance.

(2) MMP " $v s$." TIMP. MMPs can disrupt the basement membrane and allow the influx of inflammatory cells. Inhibiting MMP activity could be detrimental in immunity and in the process of re-epithelialization; ${ }^{369}$ however, in pathological fibrotic responses, neutralization of specific MMPs either with small molecules, ${ }^{157}$ inhibitors ${ }^{157}$ or by influencing TIMP expression may help restore this imbalance.

(3) Fibroblast apoptosis "vs." proliferation. The late-stage apoptosis of fibroblasts is required for successful wound healing

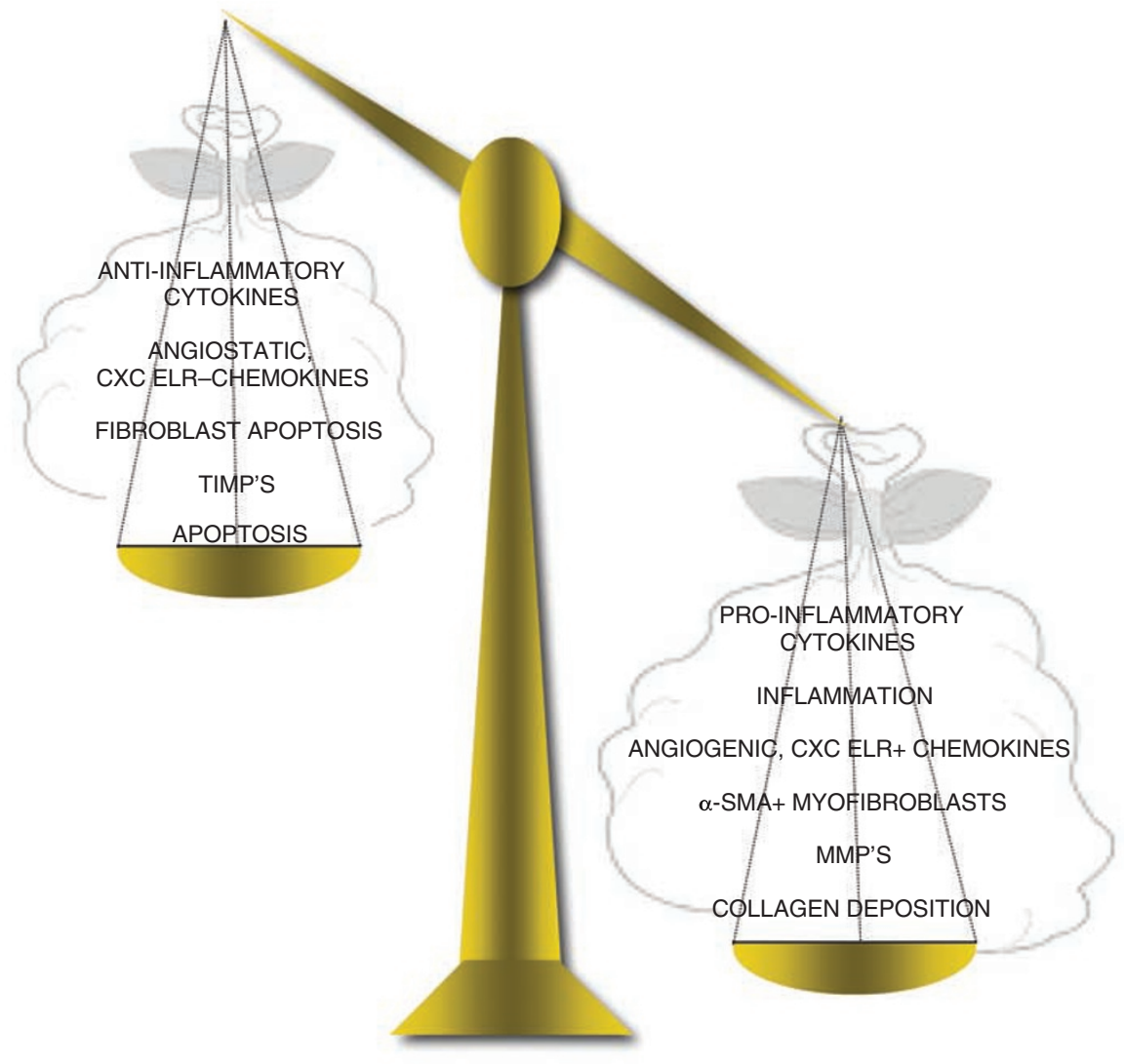

Figure 2 Imbalanced wound-healing response. For successful wound healing, a regulated response is maintained through negative feedback loops and a balance of catabolising and regenerative processes. Several imbalances may develop and lead a normal healing response into a fibrotic cascade. Excessive inflammation and the production of inflammatory and fibroblast-activating cytokines, through a breakdown in anti-inflammatory mechanisms can develop. Over-production of angiogenic CXC ELR ${ }^{+}$chemokines, the recruitment of fibrocytes and increased frequency of $\alpha$-SMA+ cells in the injury site can result in too much collagen deposition. Resetting the balance with targeted therapeutics (i.e., cytokine-blocking antibodies) may help slow the progression of fibrosis. 
and termination of collagen deposition. As mentioned above, resistance to apoptosis has been observed in fibroblasts from IPF patients. ${ }^{165-167}$ Restoring fibroblast apoptotic pathways or selectively depleting fibroblasts at the appropriate time may help slow the progression of fibrosis. Modulating local cytokine and growth factor levels could also influence fibroblast proliferation and activation indirectly.

(4) $E L R^{+}$"vs." $E L R^{-} C X C$ chemokines. The prolonged induction $\mathrm{ELR}^{+}$chemokines, due to inflammatory signals can lead to excessive vascularization. Anti-angiogenic therapy, ${ }^{370}$ an area actively pursued in cancer therapy was recently investigated in fibrotic conditions. ${ }^{371}$ Inhibiting VEGF or promoting endostatin and anastellin (endogenous inhibitors of angiogenesis) may limit inflammation and the recruitment of myofibroblasts. Neutralizing angiogenic ELR ${ }^{+}$CXC chemokines or enhancing angiostatic ELR ${ }^{-}$CXC chemokines, ${ }^{372-374}$ in combination with other therapeutic interventions, may also dramatically halt the inflammatory cascade and avoid the requirements for angiogenesis.

\section{CONCLUSION}

Pulmonary wound repair is an extremely dynamic process intersecting immunology, structural biology, and airway physiology. For successful repair a collaborative effort between these systems is essential. Dysregulation in one response can have ripple effects on others and progressively turn a well-choreographed healing response into a fibrotic lesion. Vascular damage must be quickly repaired with a fibrin-rich clot. This is followed by an influx of inflammatory cells. Chronic or recurring inflammation requires rapid resolution to avert immunopathology while providing the necessary cellular participants. Parenchymal cells that are responsive to inflammatory cues must proliferate and migrate into the damaged area, restore tissue architecture, with the inflammatory cells ultimately undergoing apoptosis to prevent excessive collagen deposition.

In pulmonary fibrotic disease states, the development and progression of the healing response has slipped out of control, disrupting many delicate balances. As discussed in this review, there are a number of compensatory and redundant processes, which all contribute to proficient healing and remodeling. With this in mind, and despite significant advances in our understanding of these pathways and balances, there is a lack of therapeutic intervention and new therapies for pulmonary fibrosis. Further studies are required to elucidate the roles of the many mediators (cytokines, chemokines and growth factors) observed in both human and animal models of pulmonary fibrosis. Greater still, pre-clinical and clinical investigations with chemokine receptor antagonists, angiogenesis inhibitors and Abs to the pro-fibrotic molecules IL-13 and TGF $\beta$ are required. A combined effort by clinicians and lab researchers across platforms and disciplines could make this a climbable mountain.

\section{DISCLOSURE}

The author declared no conflict of interest.

\section{ACKNOWLEDGMENTS}

This review was improved by peer-review and funded by the Intramural Research Program at the NIH/NIAID. Owing to space and word limitations, we apologize to the many researchers whose work we have not mentioned in this review, but who have significantly contributed to our current understanding of pulmonary fibrosis. We also thank Dr Allen Cheever for helpful comments.

(C) 2009 Society for Mucosal Immunology

\section{REFERENCES}

1. Wynn, T.A. Common and unique mechanisms regulate fibrosis in various fibroproliferative diseases. J. Clin. Invest. 117, 524-529 (2007).

2. Wynn, T.A. Fibrotic disease and the $T(H) 1 / T(H) 2$ paradigm. Nat. Rev. Immunol. 4, 583-594 (2004).

3. Tomasek, J.J., Gabbiani, G., Hinz, B., Chaponnier, C. \& Brown, R.A. Myofibroblasts and mechano-regulation of connective tissue remodelling. Nat. Rev. Mol. Cell Biol. 3, 349-363 (2002).

4. Pardo, A. \& Selman, M. Matrix metalloproteases in aberrant fibrotic tissue remodeling. Proc. Am. Thorac. Soc. 3, 383-388 (2006).

5. Raghu, G., Weycker, D., Edelsberg, J., Bradford, W.Z. \& Oster, G. Incidence and prevalence of idiopathic pulmonary fibrosis. Am. J. Resp. Crit. Care Med. 174, 810-816 (2006).

6. Daniil, Z.D. et al. A histologic pattern of nonspecific interstitial pneumonia is associated with a better prognosis than usual interstitial pneumonia in patients with cryptogenic fibrosing alveolitis. Am. J. Resp. Crit. Care Med. 160, 899-905 (1999).

7. Chambers, R.C. Role of coagulation cascade proteases in lung repair and fibrosis. Eur. Respir. J. Suppl. 44, 33s-35s (2003).

8. Hamada, N. et al. The role of high mobility group box 1 in pulmonary fibrosis. Am. J. Respir. Cell Mol. Biol. 39, 440-447 (2008).

9. Korfei, M. et al. Epithelial endoplasmic reticulum stress and apoptosis in sporadic idiopathic pulmonary fibrosis. Am. J. Resp. Crit. Care Med. 178, 838-846 (2008).

10. Dik, W.A., Zimmermann, L.J., Naber, B.A., Janssen, D.J., van Kaam, A.H. \& Versnel, M.A. Thrombin contributes to bronchoalveolar lavage fluid mitogenicity in lung disease of the premature infant. Pediatr. Pulmonol. 35, 34-41 (2003).

11. Hernandez-Rodriguez, N.A. et al. Role of thrombin in pulmonary fibrosis. Lancet 346, 1071-1073 (1995).

12. Gabazza, E.C. et al. Thrombin in the airways of asthmatic patients. Lung 177, 253-262 (1999).

13. Chen, L.B. \& Buchanan, J.M. Mitogenic activity of blood components. I. Thrombin and prothrombin. Proc. Natl. Acad. Sci. USA. 72, 131-135 (1975).

14. Bogatkevich, G.S., Tourkina, E., Silver, R.M. \& Ludwicka-Bradley, A. Thrombin differentiates normal lung fibroblasts to a myofibroblast phenotype via the proteolytically activated receptor- 1 and a protein kinase C-dependent pathway. J. Biol. Chem. 276, 45184-45192 (2001).

15. Chambers, R.C., Dabbagh, K., McAnulty, R.J., Gray, A.J., Blanc-Brude, O.P. \& Laurent, G.J. Thrombin stimulates fibroblast procollagen production via proteolytic activation of protease-activated receptor 1. Biochem. J. 333 (Part 1), 121-127 (1998).

16. Kuwano, K. et al. Essential roles of the Fas-Fas ligand pathway in the development of pulmonary fibrosis. J. Clin. Invest. 104, 13-19 (1999).

17. Vaccaro, C.A., Brody, J.S. \& Snider, G.L. Alveolar wall basement membranes in bleomycin-induced pulmonary fibrosis. Am. Rev. Respir. Dis. 132, 905-912 (1985).

18. McKeown, S., Richter, A.G., O'Kane, C., McAuley, D.F. \& Thickett, D.R. Matrix metalloproteinase expression and abnormal lung permeability are important determinants of outcome in IPF. Eur. Respir. J.32, (2008). (E-pub ahead of print)

19. Hoshino, M., Nakamura, Y., Sim, J., Shimojo, J. \& Isogai, S. Bronchial subepithelial fibrosis and expression of matrix metalloproteinase- 9 in asthmatic airway inflammation. J. Allergy Clin. Immunol. 104, 783-788 (1998).

20. Murphy, G. \& Docherty, A.J. The matrix metalloproteinases and their inhibitors. Am. J. Respir. Cell Mol. Biol. 7, 120-125 (1992).

21. Corbel, M., Belleguic, C., Boichot, E. \& Lagente, V. Involvement of gelatinases (MMP-2 and MMP-9) in the development of airway inflammation and pulmonary fibrosis. Cell Biol. Toxicol. 18, 51-61 (2002). 
22. Ruiz, V. et al. Unbalanced collagenases/TIMP-1 expression and epithelial apoptosis in experimental lung fibrosis. Am. J. Physiol. 285, L1026L1036 (2003).

23. Gadek, J.E. et al. Collagenase in the lower respiratory tract of patients with idiopathic pulmonary fibrosis. N. Engl. J. Med. 301, 737-742 (1979).

24. O'Connor, C., Odlum, C., Van Breda, A., Power, C. \& Fitzgerald, M.X. Collagenase and fibronectin in bronchoalveolar lavage fluid in patients with sarcoidosis. Thorax 43, 393-400 (1988).

25. Oggionni, T. et al. Time course of matrix metalloproteases and tissue inhibitors in bleomycin-induced pulmonary fibrosis. Eur. J. Histochem 50, 317-325 (2006).

26. O'Connor, C.M. \& FitzGerald, M.X. Matrix metalloproteases and lung disease. Thorax 49, 602-609 (1994).

27. Corry, D.B. et al. Decreased allergic lung inflammatory cell egression and increased susceptibility to asphyxiation in MMP2-deficiency. Nat Immuno/ 3, 347-353 (2002).

28. Corry, D.B. et al. Overlapping and independent contributions of MMP2 and MMP9 to lung allergic inflammatory cell egression through decreased CC chemokines. FASEB. J. 18, 995-997 (2004).

29. Erjefalt, J.S., Sundler, F. \& Persson, C.G. Eosinophils, neutrophils, and venular gaps in the airway mucosa at epithelial removal-restitution. Am. J. Resp. Crit. Care Med. 153, 1666-1674 (1996).

30. Gauldie, J. Pro: Inflammatory mechanisms are a minor component of the pathogenesis of idiopathic pulmonary fibrosis. Am. J. Resp. Crit. Care Med. 165, 1205-1206 (2002).

31. Piguet, P.F. Inflammation in idiopathic pulmonary fibrosis. Am. J. Resp. Crit. Care Med. 167, 1037; author reply (2003).

32. Strieter, R.M. Con: Inflammatory mechanisms are not a minor component of the pathogenesis of idiopathic pulmonary fibrosis. Am. J. Resp. Crit. Care Med. 165, 1206-1207; discussion 7-8 (2002).

33. Bringardner, B.D., Baran, C.P., Eubank, T.D. \& Marsh, C.B. The role of inflammation in the pathogenesis of idiopathic pulmonary fibrosis. Antioxid Redox Signal 10, 287-301 (2008).

34. Davies, H.R., Richeldi, L. \& Walters, E.H. Immunomodulatory agents for idiopathic pulmonary fibrosis. Cochrane Database Syst. Rev. CD003134 (2003).

35. Richeldi, L., Davies, H.R., Ferrara, G. \& Franco, F. Corticosteroids for idiopathic pulmonary fibrosis. Cochrane Database Syst. Rev. CD002880 (2003).

36. Selman, M., King, T.E. \& Pardo, A. Idiopathic pulmonary fibrosis: prevailing and evolving hypotheses about its pathogenesis and implications for therapy. Ann. Intern. Med. 134, 136-151 (2001).

37. Elovic, A.E. et al. IL-4-dependent regulation of TGF-alpha and TGFbeta1 expression in human eosinophils. J. Immunol. 160, 6121-6127 (1998).

38. Minshall, E.M. et al. Eosinophil-associated TGF-beta1 mRNA expression and airways fibrosis in bronchial asthma. Am. J. Respir. Cell Mol. Biol. 17, 326-333 (1997).

39. Ohno, I. et al. Transforming growth factor beta 1 (TGF beta 1) gene expression by eosinophils in asthmatic airway inflammation. Am. J. Respir. Cell Mol. Biol. 15, 404-409 (1996).

40. Wenzel, S.E. et al. TGF-beta and IL-13 synergistically increase eotaxin-1 production in human airway fibroblasts. J. Immunol. 169, 4613-4619 (2002).

41. Zagai, U., Dadfar, E., Lundahl, J., Venge, P. \& Skold, C.M. Eosinophil cationic protein stimulates TGF-beta1 release by human lung fibroblasts in vitro. Inflammation 30, 153-160 (2007).

42. Moodley, Y. et al. Macrophage recognition and phagocytosis of apoptotic fibroblasts is critically dependent on fibroblast-derived thrombospondin 1 and CD36. Am. J. Pathol. 162, 771-779 (2003).

43. Nakagome, K., Dohi, M., Okunishi, K., Tanaka, R., Miyazaki, J. \& Yamamoto, K. In vivo IL-10 gene delivery attenuates bleomycin induced pulmonary fibrosis by inhibiting the production and activation of TGFbeta in the lung. Thorax 61, 886-894 (2006).

44. Janeway, C.A. Jr \& Medzhitov, R. Innate immune recognition. Annu. Rev. Immunol. 20, 197-216 (2002).

45. Matzinger, P. The danger model: a renewed sense of self. Science 296, 301-305 (2002).

46. Holgate, S.T. Pathogenesis of asthma. Clin. Exp. Allergy 38, 872-897 (2008).
47. Agostini, C. \& Gurrieri, C. Chemokine/cytokine cocktail in idiopathic pulmonary fibrosis. Proc. Am. Thorac Soc. 3, 357-363 (2006).

48. Fertin, C., Nicolas, J.F., Gillery, P., Kalis, B., Banchereau, J. \& Maquart, F.X. Interleukin-4 stimulates collagen synthesis by normal and scleroderma fibroblasts in dermal equivalents. Cell Mol. Biol. 37, 823-829 (1991).

49. Sempowski, G.D., Beckmann, M.P., Derdak, S. \& Phipps, R.P. Subsets of murine lung fibroblasts express membrane-bound and soluble IL-4 receptors. Role of IL-4 in enhancing fibroblast proliferation and collagen synthesis. J. Immunol. 152, 3606-3614 (1994).

50. Strutz, F. et al. TGF-beta 1 induces proliferation in human renal fibroblasts via induction of basic fibroblast growth factor (FGF-2). Kidney Int. 59, 579-592 (2001).

51. Wynn, T.A. IL-13 effector functions. Annu. Rev. Immunol. 21, 425-456 (2003).

52. Emura, M., Nagai, S., Takeuchi, M., Kitaichi, M. \& Izumi, T. In vitro production of B cell growth factor and B cell differentiation factor by peripheral blood mononuclear cells and bronchoalveolar lavage $T$ lymphocytes from patients with idiopathic pulmonary fibrosis. Clin. Exp. Immunol. 82, 133-139 (1990).

53. Wallace, W.A., Ramage, E.A., Lamb, D. \& Howie, S.E. A type 2 (Th2-like) pattern of immune response predominates in the pulmonary interstitium of patients with cryptogenic fibrosing alveolitis (CFA). Clin. Exp. Immunol. 101, 436-441 (1995).

54. Buttner, C. et al. Local production of interleukin-4 during radiationinduced pneumonitis and pulmonary fibrosis in rats: macrophages as a prominent source of interleukin-4. Am. J. Respir. Cell Mol. Biol. 17, 315-325 (1997).

55. Booth, M. et al. Periportal fibrosis in human Schistosoma mansoni infection is associated with low IL-10, low IFN-gamma, high TNF-alpha, or low RANTES, depending on age and gender. J. Immunol. 172, 1295-1303 (2004).

56. Pauleau, A.L., Rutschman, R., Lang, R., Pernis, A., Watowich, S.S. \& Murray, P.J. Enhancer-mediated control of macrophage-specific arginase I expression. J. Immunol. 172, 7565-7573 (2004).

57. Liu, T. et al. Regulation of found in inflammatory zone 1 expression in bleomycin-induced lung fibrosis: role of IL-4/IL-13 and mediation via STAT-6. J. Immunol. 173, 3425-3431 (2004).

58. Lee, E., Yook, J., Haa, K. \& Chang, H.W. Induction of Ym1/2 in mouse bone marrow-derived mast cells by IL- 4 and identification of $Y \mathrm{~m} 1 / 2$ in connective tissue type-like mast cells derived from bone marrow cells cultured with IL-4 and stem cell factor. Immunol. Cell Biol. 83, 468-474 (2005).

59. Martinez-Pomares, L. et al. Analysis of mannose receptor regulation by $\mathrm{IL}-4, \mathrm{IL}-10$, and proteolytic processing using novel monoclonal antibodies. J. Leukoc. Biol. 73, 604-613 (2003).

60. Song, E., Ouyang, N., Horbelt, M., Antus, B., Wang, M. \& Exton, M.S. Influence of alternatively and classically activated macrophages on fibrogenic activities of human fibroblasts. Cell Immunol. 204, 19-28 (2000).

61. Hesse, M. et al. Differential regulation of nitric oxide synthase-2 and arginase- 1 by type 1/type 2 cytokines in vivo: granulomatous pathology is shaped by the pattern of L-arginine metabolism. J. Immunol. 167, 6533-6544 (2001).

62. Prasse, A. et al. A vicious circle of alveolar macrophages and fibroblasts perpetuates pulmonary fibrosis via CCL18. Am. J. Resp. Crit. Care Med. 173, 781-792 (2006).

63. Pulichino, A.M. et al. Identification of transforming growth factor beta1driven genetic programs of acute lung fibrosis. Am. J. Respir. Cell Mol. Biol. 39, 324-336 (2008).

64. Vidal, B. et al. Fibrinogen drives dystrophic muscle fibrosis via a TGFbeta/alternative macrophage activation pathway. Genes Dev. 22, 1747-1752 (2008).

65. Gangadharan, B. et al. Murine gammaherpesvirus-induced fibrosis is associated with the development of alternatively activated macrophages. J. Leukoc. Biol. 84, 50-58 (2008).

66. Emad, A. \& Emad, Y. Increased granulocyte-colony stimulating factor (G-CSF) and granulocyte-macrophage colony stimulating factor (GM-CSF) levels in BAL fluid from patients with sulfur mustard gas-induced pulmonary fibrosis. J. Aerosol. Med. 20, 352-360 (2007).

67. Baran, C.P. et al. Important roles for macrophage colony-stimulating factor, CC chemokine ligand 2, and mononuclear phagocytes in the 
pathogenesis of pulmonary fibrosis. Am. J. Resp. Crit. Care Med. 176, 78-89 (2007).

68. Ishida, Y. et al. Essential roles of the CC chemokine ligand 3-CC chemokine receptor 5 axis in bleomycin-induced pulmonary fibrosis through regulation of macrophage and fibrocyte infiltration. Am. J. Pathol. 170, 843-854 (2007).

69. Trujillo, G., O'Connor, E.C., Kunkel, S.L. \& Hogaboam, C.M. A novel mechanism for CCR4 in the regulation of macrophage activation in bleomycin-induced pulmonary fibrosis. Am. J. Pathol. 172, 1209-1221 (2008).

70. Takatsu, K. \& Nakajima, H. IL-5 and eosinophilia. Curr. Opin. Immunol. 20, 288-294 (2008).

71. Reiman, R.M. et al. Interleukin-5 (IL-5) augments the progression of liver fibrosis by regulating IL-13 activity. Infect Immun. 74, 1471-1479 (2006).

72. Eklund, K.K., Ghildyal, N., Austen, K.F. \& Stevens, R.L. Induction by IL-9 and suppression by IL-3 and IL-4 of the levels of chromosome 14derived transcripts that encode late-expressed mouse mast cell proteases. J. Immunol. 151, 4266-4273 (1993).

73. Tomimori, Y. et al. Involvement of mast cell chymase in bleomycininduced pulmonary fibrosis in mice. Eur. J. Pharmacol. 478, 179-185 (2003).

74. Garbuzenko, E. et al. Human mast cells stimulate fibroblast proliferation, collagen synthesis and lattice contraction: a direct role for mast cells in skin fibrosis. Clin. Exp. Allergy 32, 237-246 (2002).

75. Masuda, T. et al. Mast cells play a partial role in allergen-induced subepithelial fibrosis in a murine model of allergic asthma. Clin. Exp. Allergy 33, 705-713 (2003).

76. Pesce, J. et al. The IL-21 receptor augments Th2 effector function and alternative macrophage activation. J. Clin. Invest. 116, 2044-2055 (2006).

77. Frohlich, A. et al. IL-21 receptor signaling is integral to the development of Th2 effector responses in vivo. Blood 109, 2023-2031 (2007).

78. Webb, D.C., Mahalingam, S., Cai, Y., Matthaei, K.I., Donaldson, D.D. \& Foster, P.S. Antigen-specific production of interleukin (IL)-13 and IL-5 cooperate to mediate IL-4Ralpha-independent airway hyperreactivity. Eur. J. Immunol. 33, 3377-3385 (2003).

79. Blease, K. et al. Stat6-deficient mice develop airway hyperresponsiveness and peribronchial fibrosis during chronic fungal asthma. Am. J. Pathol. 160, 481-490 (2002).

80. Fichtner-Feigl, S. et al. Induction of IL-13 triggers TGF-beta1-dependent tissue fibrosis in chronic 2,4,6-trinitrobenzene sulfonic acid colitis. J. Immunol. 178, 5859-5870 (2007).

81. Fichtner-Feigl, S., Young, C.A., Kitani, A., Geissler, E.K., Schlitt, H.J. \& Strober, W. IL-13 Signaling via IL-13Ralpha(2) Induces Major Downstream Fibrogenic Factors Mediating Fibrosis in Chronic TNBS Colitis. Gastroenterology 135, 2003-2013(2008).

82. Shimamura, T., Fujisawa, T., Husain, S.R., Kioi, M., Nakajima, A. \& Puri, R.K. Novel role of IL-13 in fibrosis induced by nonalcoholic steatohepatitis and its amelioration by IL-13R-directed cytotoxin in a rat model. J. Immunol. 181, 4656-4665 (2008).

83. Munitz, A., Brandt, E.B., Mingler, M., Finkelman, F.D. \& Rothenberg, M.E. Distinct roles for IL-13 and IL-4 via IL-13 receptor alpha1 and the type II IL-4 receptor in asthma pathogenesis. Proc. Natl. Acad. Sci. USA. 105, 7240-7245 (2008).

84. Kaviratne, M. et al. IL-13 activates a mechanism of tissue fibrosis that is completely TGF-beta independent. J. Immunol. 173, 4020-4029 (2004).

85. Ingram, J.L., Rice, A.B., Geisenhoffer, K., Madtes, D.K. \& Bonner, J.C. $\mathrm{IL}-13$ and IL-1 beta promote lung fibroblast growth through coordinated up-regulation of PDGF-AA and PDGF-Ralpha. FASEB J. 18, 1132-1134 (2004).

86. Zhu, Z. et al. Pulmonary expression of interleukin-13 causes inflammation, mucus hypersecretion, subepithelial fibrosis, physiologic abnormalities, and eotaxin production. J. Clin. Invest. 103, 779-788 (1999).

87. Blease, K., Jakubzick, C., Westwick, J., Lukacs, N., Kunkel, S.L. \& Hogaboam, C.M. Therapeutic effect of IL-13 immunoneutralization during chronic experimental fungal asthma. J. Immunol. 166, 5219-5224 (2001).

88. Yang, G. et al. Anti-IL-13 monoclonal antibody inhibits airway hyperresponsiveness, inflammation and airway remodeling. Cytokine $\mathbf{2 8}$, 224-232 (2004).
89. Belperio, J.A. et al. Interaction of IL-13 and C10 in the pathogenesis of bleomycin-induced pulmonary fibrosis. Am. J. Respir. Cell Mol. Biol. 27, 419-427 (2002).

90. Jakubzick, C. et al. Therapeutic attenuation of pulmonary fibrosis via targeting of IL-4- and IL-13-responsive cells. J. Immunol. 171, 26842693 (2003).

91. Kolodsick, J.E. et al. Protection from fluorescein isothiocyanate-induced fibrosis in IL-13-deficient, but not IL-4-deficient, mice results from impaired collagen synthesis by fibroblasts. J. Immunol. 172, 4068-4076 (2004).

92. Malavia, N.K., Mih, J.D., Raub, C.B., Dinh, B.T. \& George, S.C. IL-13 induces a bronchial epithelial phenotype that is profibrotic. Respir. Res. 9, 27 (2008).

93. Murray, L.A. et al. Hyper-responsiveness of IPF/UIP fibroblasts: interplay between TGFbeta1, IL-13 and CCL2. Int. J. Biochem. Cell Biol. 40, 2174-2182 (2008).

94. Kraft, M., Lewis, C., Pham, D. \& Chu, H.W. IL-4, IL-13, and dexamethasone augment fibroblast proliferation in asthma. J. Allergy Clin. Immunol. 107, 602-606 (2001).

95. Lee, C.G. et al. Interleukin-13 induces tissue fibrosis by selectively stimulating and activating transforming growth factor beta(1). J. Exp. Med. 194, 809-821 (2001).

96. Letterio, J.J. \& Roberts, A.B. Regulation of immune responses by TGFbeta. Annu. Rev. Immunol. 16, 137-161 (1998).

97. Assoian, R.K. et al. Expression and secretion of type beta transforming growth factor by activated human macrophages. Proc. Natl. Acad. Sci. USA. 84, 6020-6024 (1987).

98. Grotendorst, G.R., Smale, G. \& Pencev, D. Production of transforming growth factor beta by human peripheral blood monocytes and neutrophils. J. Cell Physiol. 140, 396-402 (1989).

99. Khalil, N., Corne, S., Whitman, C. \& Yacyshyn, H. Plasmin regulates the activation of cell-associated latent TGF-beta 1 secreted by rat alveolar macrophages after in vivo bleomycin injury. Am. J. Respir. Cell Mol. Biol. 15, 252-259 (1996).

100. Gressner, A.M., Lahme, B. \& Roth, S. Attenuation of TGF-beta-induced apoptosis in primary cultures of hepatocytes by calpain inhibitors. Biochem. Biophys. Res. Commun. 231, 457-462 (1997).

101. Munger, J.S. et al. The integrin alpha $v$ beta 6 binds and activates latent TGF beta 1: a mechanism for regulating pulmonary inflammation and fibrosis. Cell 96, 319-328 (1999).

102. Yu, Q. \& Stamenkovic, I. Cell surface-localized matrix metalloproteinase-9 proteolytically activates TGF-beta and promotes tumor invasion and angiogenesis. Genes Dev. 14, 163-176 (2000).

103. Szardening-Kirchner, C., Konrad, L., Hauck, E.W., Haag, S.M., Eickelberg, O. \& Weidner, W. Upregulation of mRNA expression of MCP-1 by TGF-beta1 in fibroblast cells from Peyronie's disease. World J. Urol. (2008) (E-pub ahead of print).

104. Coker, R.K. et al. Transforming growth factors-beta 1, -beta 2, and -beta 3 stimulate fibroblast procollagen production in vitro but are differentially expressed during bleomycin-induced lung fibrosis. Am. J. Pathol. 150, 981-991 (1997).

105. Chen, W., Perruche, S. \& Li, J. CD4+CD25+ T regulatory cells and TGFbeta in mucosal immune system: the good and the bad. Curr. Med. Chem. 14, 2245-2249 (2007).

106. Huber, S. \& Schramm, C. TGF-beta and CD4+CD25+ regulatory T cells. Front Biosci. 11, 1014-1023 (2006).

107. Wahl, S.M., Swisher, J., McCartney-Francis, N. \& Chen, W. TGF-beta: the perpetrator of immune suppression by regulatory $T$ cells and suicidal T cells. J. Leukoc. Biol. 76, 15-24 (2004).

108. Sime, P.J., Xing, Z., Graham, F.L., Csaky, K.G. \& Gauldie, J Adenovector-mediated gene transfer of active transforming growth factor-beta1 induces prolonged severe fibrosis in rat lung. J. Clin. Invest. 100, 768-776 (1997).

109. Flanders, K.C. Smad3 as a mediator of the fibrotic response. Int. J. Exp. Pathol. 85, 47-64 (2004).

110. Flanders, K.C. et al. Mice lacking Smad3 are protected against cutaneous injury induced by ionizing radiation. Am. J. Pathol. 160, 1057-1068 (2002).

111. Lakos, G. et al. Targeted disruption of TGF-beta/Smad3 signaling modulates skin fibrosis in a mouse model of scleroderma. Am. J. Pathol. 165, 203-217 (2004).

112. Border, W.A. et al. Natural inhibitor of transforming growth factor-beta protects against scarring in experimental kidney disease. Nature $\mathbf{3 6 0}$ 361-364 (1992). 
113. Inazaki, K. et al. Smad3 deficiency attenuates renal fibrosis, inflammation, and apoptosis after unilateral ureteral obstruction. Kidney Int. 66, 597-604 (2004).

114. Sato, M., Muragaki, Y., Saika, S., Roberts, A.B. \& Ooshima, A. Targeted disruption of TGF-beta1/Smad3 signaling protects against renal tubulointerstitial fibrosis induced by unilateral ureteral obstruction. J. Clin Invest. 112, 1486-1494 (2003).

115. Stramer, B.M., Austin, J.S., Roberts, A.B. \& Fini, M.E. Selective reduction of fibrotic markers in repairing corneas of mice deficient in Smad3. J. Cell Physiol. 203, 226-232 (2005).

116. Bonniaud, P. et al. Smad3 null mice develop airspace enlargement and are resistant to TGF-beta-mediated pulmonary fibrosis. J. Immunol. 173, 2099-2108 (2004).

117. Zhao, J. et al. Smad3 deficiency attenuates bleomycin-induced pulmonary fibrosis in mice. Am. J. Physiol. 282, L585-L593 (2002).

118. Ashcroft, G.S. et al. Mice lacking Smad3 show accelerated wound healing and an impaired local inflammatory response. Nat. Cell Biol. 1, 260-266 (1999).

119. Ma, L.J. et al. Transforming growth factor-beta-dependent and independent pathways of induction of tubulointerstitial fibrosis in beta6(-/-) mice. Am. J. Pathol. 163, 1261-1273 (2003).

120. Proudfoot, A.E. Chemokine receptors: multifaceted therapeutic targets. Nat. Rev. Immunol. 2, 106-115 (2002).

121. Blease, K., Mehrad, B., Lukacs, N.W., Kunkel, S.L., Standiford, T.J. \& Hogaboam, C.M. Antifungal and airway remodeling roles for murine monocyte chemoattractant protein-1/CCL2 during pulmonary exposure to Asperigillus fumigatus conidia. J. Immunol. 166, 1832-1842 (2001).

122. Car, B.D., Meloni, F., Luisetti, M., Semenzato, G., Gialdroni-Grassi, G. \& Walz, A. Elevated IL-8 and MCP-1 in the bronchoalveolar lavage fluid of patients with idiopathic pulmonary fibrosis and pulmonary sarcoidosis. Am. J. Resp. Crit. Care Med. 149 (3 Part 1), 655-659 (1994).

123. Emad, A. \& Emad, Y. Relationship between eosinophilia and levels of chemokines (CCL5 and CCL11) and IL-5 in bronchoalveolar lavage fluid of patients with mustard gas-induced pulmonary fibrosis. J. Clin. Immunol. 28, 298-305 (2008).

124. Huaux, F. et al. Role of Eotaxin-1 (CCL11) and CC chemokine receptor 3 (CCR3) in bleomycin-induced lung injury and fibrosis. Am. J. Pathol. 167, 1485-1496 (2005).

125. Puxeddu, I., Bader, R., Piliponsky, A.M., Reich, R., Levi-Schaffer, F. \& Berkman, N. The CC chemokine eotaxin/CCL11 has a selective profibrogenic effect on human lung fibroblasts. J. Allergy Clin. Immunol. 117, 103-110 (2006)

126. Rose, C.E. Jr, Sung, S.S. \& Fu, S.M. Significant involvement of CCL2 (MCP-1) in inflammatory disorders of the lung. Microcirculation 10, 273 288 (2003).

127. Zhang, K., Gharaee-Kermani, M., Jones, M.L., Warren, J.S. \& Phan, S.H. Lung monocyte chemoattractant protein-1 gene expression in bleomycin-induced pulmonary fibrosis. J. Immunol. 153, 4733-4741 (1994).

128. Gharaee-Kermani, M., McCullumsmith, R.E., Charo, I.F., Kunkel, S.L. \& Phan, S.H. CC-chemokine receptor 2 required for bleomycin-induced pulmonary fibrosis. Cytokine 24, 266-276 (2003).

129. Wu, Y., Li, Y.Y., Matsushima, K., Baba, T. \& Mukaida, N. CCL3-CCR5 axis regulates intratumoral accumulation of leukocytes and fibroblasts and promotes angiogenesis in murine lung metastasis process. J. Immunol. 181, 6384-6393 (2008).

130. Moore, B.B. et al. CCR2-mediated recruitment of fibrocytes to the alveolar space after fibrotic injury. Am. J. Pathol. 166, 675-684 (2005).

131. Abe, R., Donnelly, S.C., Peng, T., Bucala, R. \& Metz, C.N. Peripheral blood fibrocytes: differentiation pathway and migration to wound sites. J. Immunol. 166, 7556-7562 (2001).

132. van Deventer, H.W. et al. C-C chemokine receptor 5 on pulmonary fibrocytes facilitates migration and promotes metastasis via matrix metalloproteinase 9. Am. J. Pathol. 173, 253-264 (2008).

133. Phillips, R.J. et al. Circulating fibrocytes traffic to the lungs in response to CXCL12 and mediate fibrosis. J. Clin. Invest. 114, 438-446 (2004).

134. Quan, T.E., Cowper, S., Wu, S.P., Bockenstedt, L.K. \& Bucala, R. Circulating fibrocytes: collagen-secreting cells of the peripheral blood. Int. J. Biochem. Cell Biol. 36, 598-606 (2004).

135. Bucala, R., Spiegel, L.A., Chesney, J., Hogan, M. \& Cerami, A. Circulating fibrocytes define a new leukocyte subpopulation that mediates tissue repair. Mol. Med. 1, 71-81 (1994).
136. Schmidt, M., Sun, G., Stacey, M.A., Mori, L. \& Mattoli, S. Identification of circulating fibrocytes as precursors of bronchial myofibroblasts in asthma. J. Immunol. 171, 380-389 (2003).

137. Strieter, R.M., Gomperts, B.N. \& Keane, M.P. The role of CXC chemokines in pulmonary fibrosis. J. Clin. Invest. 117, 549-556 (2007)

138. Semenza, G.L. Vasculogenesis, angiogenesis, and arteriogenesis: mechanisms of blood vessel formation and remodeling. J. Cell Biochem. 102, 840-847 (2007)

139. Keane, M.P. et al. The CXC chemokines, IL-8 and IP-10, regulate angiogenic activity in idiopathic pulmonary fibrosis. J. Immunol. 159, 1437-1443 (1997).

140. Antoniou, K.M. et al. Different angiogenic activity in pulmonary sarcoidosis and idiopathic pulmonary fibrosis. Chest 130, 982-988 (2006).

141. Burdick, M.D. et al. CXCL11 attenuates bleomycin-induced pulmonary fibrosis via inhibition of vascular remodeling. Am. J. Resp. Crit. Care Med. 171, 261-268 (2005).

142. Keane, M.P. et al. IFN-gamma-inducible protein-10 attenuates bleomycin-induced pulmonary fibrosis via inhibition of angiogenesis. J. Immunol. 163, 5686-5692 (1999).

143. Keane, M.P. et al. Neutralization of the CXC chemokine, macrophage inflammatory protein-2, attenuates bleomycin-induced pulmonary fibrosis. J. Immunol. 162, 5511-5518 (1999).

144. Peao, M.N., Aguas, A.P., de Sa, C.M. \& Grande, N.R. Neoformation of blood vessels in association with rat lung fibrosis induced by bleomycin. Anat. Rec. 238, 57-67 (1994).

145. Driscoll, K.E., Maurer, J.K., Poynter, J., Higgins, J., Asquith, T. \& Miller, N.S. Stimulation of rat alveolar macrophage fibronectin release in a cadmium chloride model of lung injury and fibrosis. Toxicol. Appl. Pharmacol. 116, 30-37 (1992).

146. Kadler, K.E., Hill, A. \& Canty-Laird, E.G. Collagen fibrillogenesis: fibronectin, integrins, and minor collagens as organizers and nucleators. Curr. Opin. Cell Biol. 20, 495-501 (2008).

147. Lacronique, J.G., Rennard, S.I., Bitterman, P.B., Ozaki, T. \& Crystal, R.G. Alveolar macrophages in idiopathic pulmonary fibrosis have glucocorticoid receptors, but glucocorticoid therapy does not suppress alveolar macrophage release of fibronectin and alveolar macrophage derived growth factor. Am. Rev. Respir. Dis. 130, 450-456 (1984)

148. Muro, A.F. et al. An essential role for fibronectin extra type III domain A in pulmonary fibrosis. Am. J. Resp. Crit. Care Med. 177, 638-645 (2008).

149. Hernnas, J., Nettelbladt, O., Bjermer, L., Sarnstrand, B., Malmstrom, A \& Hallgren, R. Alveolar accumulation of fibronectin and hyaluronan precedes bleomycin-induced pulmonary fibrosis in the rat. Eur. Respir. J. 5, 404-410 (1992).

150. Lazenby, A.J., Crouch, E.C., McDonald, J.A. \& Kuhn, C. III Remodeling of the lung in bleomycin-induced pulmonary fibrosis in the rat. An immunohistochemical study of laminin, type IV collagen, and fibronectin. Am. Rev. Respir. Dis. 142, 206-214 (1990).

151. Iwano, M., Plieth, D., Danoff, T.M., Xue, C., Okada, H. \& Neilson, E.G. Evidence that fibroblasts derive from epithelium during tissue fibrosis. J. Clin. Invest. 110, 341-350 (2002).

152. Venkatesan, N., Roughley, P.J. \& Ludwig, M.S. Proteoglycan expression in bleomycin lung fibroblasts: role of transforming growth factor-beta(1) and interferon-gamma. Am. J. Physiol. 283, L806-L814 (2002).

153. Bensadoun, E.S., Burke, A.K., Hogg, J.C. \& Roberts, C.R. Proteoglycan deposition in pulmonary fibrosis. Am. J. Resp. Crit. Care Med. 154 (6 Part 1), 1819-1828 (1996).

154. McGowan, S.E. Extracellular matrix and the regulation of lung development and repair. FASEB J. 6, 2895-2904 (1992).

155. Parra, E.R., Kairalla, R.A., de Carvalho, C.R. \& Capelozzi, V.L. Abnormal deposition of collagen/elastic vascular fibres and prognostic significance in idiopathic interstitial pneumonias. Thorax 62, 428-437 (2007).

156. Farahani, R.M. \& Kloth, L.C. The hypothesis of "biophysical matrix contraction": wound contraction revisited. Int. Wound J. 5, 477-482 (2008).

157. Mirastschijski, U., Haaksma, C.J., Tomasek, J.J. \& Agren, M.S. Matrix metalloproteinase inhibitor GM 6001 attenuates keratinocyte migration contraction and myofibroblast formation in skin wounds. Exp. Cell Res. 299, 465-475 (2004).

158. Hinz, B. Masters and servants of the force: the role of matrix adhesions in myofibroblast force perception and transmission. Eur. J. Cell Biol. 85, 175-181 (2006). 
159. Singer, I.I. Fibronexus formation is an early event during fibronectininduced restoration of more normal morphology and substrate adhesion patterns in transformed hamster fibroblasts. J. Cell Sci. 56, 1-20 (1982).

160. Thannickal, V.J. \& Horowitz, J.C. Evolving concepts of apoptosis in idiopathic pulmonary fibrosis. Proc. Am. Thorac. Soc. 3, 350-356 (2006).

161. Garcia-Alvarez, J. et al. Tissue inhibitor of metalloproteinase-3 is upregulated by transforming growth factor-beta1 in vitro and expressed in fibroblastic foci in vivo in idiopathic pulmonary fibrosis. Exp. Lung Res. 32, 201-214 (2006).

162. Gill, S.E. \& Parks, W.C. Metalloproteinases and their inhibitors: regulators of wound healing. Int. J. Biochem. Cell Biol. 40, 1334-1347 (2008).

163. Selman, M. et al. TIMP-1, $-2,-3$, and -4 in idiopathic pulmonary fibrosis. A prevailing nondegradative lung microenvironment? Am. J. Physiol. 279, L562-L574 (2000).

164. Fattman, C.L. Apoptosis in pulmonary fibrosis: too much or not enough? Antioxid Redox Signal 10, 379-385 (2008).

165. Moodley, Y.P. et al. Comparison of the morphological and biochemical changes in normal human lung fibroblasts and fibroblasts derived from lungs of patients with idiopathic pulmonary fibrosis during FasL-induced apoptosis. J. Pathol. 202, 486-495 (2004).

166. Buhling, F. et al. Altered expression of membrane-bound and soluble CD95/Fas contributes to the resistance of fibrotic lung fibroblasts to FasL induced apoptosis. Respir. Res. 6, 37 (2005).

167. Maeyama, T. et al. Upregulation of Fas-signalling molecules in lung epithelial cells from patients with idiopathic pulmonary fibrosis. Eur. Respir. J. 17, 180-189 (2001).

168. Moodley, Y.P. et al. Inverse effects of interleukin- 6 on apoptosis of fibroblasts from pulmonary fibrosis and normal lungs. Am. J. Respir. Cell Mol. Biol. 29, 490-498 (2003).

169. Plataki, M., Koutsopoulos, A.V., Darivianaki, K., Delides, G., Siafakas, N.M. \& Bouros, D. Expression of apoptotic and antiapoptotic markers in epithelial cells in idiopathic pulmonary fibrosis. Chest 127, 266-274 (2005).

170. Ramos, C. et al. Fibroblasts from idiopathic pulmonary fibrosis and normal lungs differ in growth rate, apoptosis, and tissue inhibitor of metalloproteinases expression. Am. J. Respir. Cell Mol. Biol. 24, 591-598 (2001).

171. Frankel, S.K. et al. TNF-alpha sensitizes normal and fibrotic human lung fibroblasts to Fas-induced apoptosis. Am. J. Respir. Cell Mol. Biol. 34, 293-304 (2006).

172. Erjefalt, J.S., Erjefalt, I., Sundler, F. \& Persson, C.G. In vivo restitution of airway epithelium. Cell Tissue Res. 281, 305-316 (1995).

173. Zahm, J.M. et al. Cell migration and proliferation during the in vitro wound repair of the respiratory epithelium. Cell Motil Cytoskeleton 37, 33-43 (1997).

174. Kheradmand, F., Folkesson, H.G., Shum, L., Derynk, R., Pytela, R. \& Matthay, M.A. Transforming growth factor-alpha enhances alveolar epithelial cell repair in a new in vitro model. Am. J. Physiol. 267 (6 Part 1), L728-L738 (1994).

175. Chilosi, M. et al. Abnormal re-epithelialization and lung remodeling in idiopathic pulmonary fibrosis: the role of deltaN-p63. Lab Invest 82, 1335-1345 (2002)

176. Erjefalt, J.S. \& Persson, C.G. Airway epithelial repair: breathtakingly quick and multipotentially pathogenic. Thorax 52, 1010-1012 (1997).

177. Farooqui, R. \& Fenteany, G. Multiple rows of cells behind an epithelial wound edge extend cryptic lamellipodia to collectively drive cell-sheet movement. J. Cell Sci. 118 (Part 1), 51-63 (2005).

178. Zhao, M., Song, B., Pu, J., Forrester, J.V. \& McCaig, C.D. Direct visualization of a stratified epithelium reveals that wounds heal by unified sliding of cell sheets. FASEB J. 17, 397-406 (2003).

179. Dunsmore, S.E. et al. Matrilysin expression and function in airway epithelium. J. Clin. Invest. 102, 1321-1331 (1998).

180. McGuire, J.K., Li, Q. \& Parks, W.C. Matrilysin (matrix metalloproteinase7) mediates $E$-cadherin ectodomain shedding in injured lung epithelium. Am. J. Pathol. 162, 1831-1843 (2003).

181. Chen, P. et al. Tissue inhibitor of metalloproteinase- 1 moderates airway re-epithelialization by regulating matrilysin activity. Am. J. Pathol. 172, 1256-1270 (2008)

182. Goss, C.H. \& Rosenfeld, M. Update on cystic fibrosis epidemiology. Curr. Opin. Pulm Med. 10, 510-514 (2004).
183. Anderson, M.P. et al. Demonstration that CFTR is a chloride channel by alteration of its anion selectivity. Science 253, 202-205 (1991).

184. Jacquot, J., Tabary, O. \& Clement, A. Hyperinflammation in airways of cystic fibrosis patients: what's new? Expert Rev. Mol. Diagn. 8, 359-363 (2008).

185. Koch, C. \& Hoiby, N. Diagnosis and treatment of cystic fibrosis. Respiration 67, 239-247 (2000).

186. Ratjen, F. Recent advances in cystic fibrosis. Paediatr Respir Rev. 9, 144-148 (2008).

187. Saiman, L. Microbiology of early CF lung disease. Paediatr Respir Rev. 5 (Suppl A), S367-S369 (2004).

188. Hansen, C.R., Pressler, T., Koch, C. \& Hoiby, N. Long-term azitromycin treatment of cystic fibrosis patients with chronic Pseudomonas aeruginosa infection; an observational cohort study. J. Cyst. Fibros 4, 35-40 (2005).

189. Pai, V.B. \& Nahata, M.C. Efficacy and safety of aerosolized tobramycin in cystic fibrosis. Pediatr. Pulmonol. 32, 314-327 (2001).

190. Westerman, E.M., Le Brun, P.P., Touw, D.J., Frijlink, H.W. \& Heijerman, H.G. Effect of nebulized colistin sulphate and colistin sulphomethate on lung function in patients with cystic fibrosis: a pilot study. J. Cyst. Fibros 3, 23-28 (2004).

191. Nichols, D., Chmiel, J. \& Berger, M. Chronic inflammation in the cystic fibrosis lung: alterations in inter- and intracellular signaling. Clin. Rev. Allergy Immunol. 34, 146-162 (2008).

192. Soferman, R. Immunopathophysiologic mechanisms of cystic fibrosis lung disease. Isr. Med. Assoc. J. 8, 44-48 (2006).

193. Regamey, N. et al. Increased airway smooth muscle mass in children with asthma, cystic fibrosis, and non-cystic fibrosis bronchiectasis. Am J. Resp. Crit. Care Med. 177, 837-843 (2008).

194. Gaggar, A. et al. Matrix metalloprotease- 9 dysregulation in lower airway secretions of cystic fibrosis patients. Am. J. Physiol. 293, L96-L104 (2007).

195. Delacourt, C. et al. Imbalance between $95 \mathrm{kDa}$ type IV collagenase and tissue inhibitor of metalloproteinases in sputum of patients with cystic fibrosis. Am. J. Resp. Crit. Care Med. 152, 765-774 (1995).

196. Sagel, S.D., Kapsner, R.K. \& Osberg, I. Induced sputum matrix metalloproteinase- 9 correlates with lung function and airway inflammation in children with cystic fibrosis. Pediatr. Pulmonol. 39, 224-232 (2005)

197. Hajj, R., Lesimple, P., Nawrocki-Raby, B., Birembaut, P., Puchelle, E. \& Coraux, C. Human airway surface epithelial regeneration is delayed and abnormal in cystic fibrosis. J. Pathol. 211, 340-350 (2007).

198. Clarke, L.L., Grubb, B.R., Gabriel, S.E., Smithies, O., Koller, B.H. \& Boucher, R.C. Defective epithelial chloride transport in a gene-targeted mouse model of cystic fibrosis. Science 257, 1125-1128 (1992).

199. Kent, G. et al. Lung disease in mice with cystic fibrosis. J. Clin. Invest. 100, 3060-3069 (1997).

200. Snouwaert, J.N. et al. An animal model for cystic fibrosis made by gene targeting. Science 257, 1083-1088 (1992).

201. Bensalem, N. et al. Down-regulation of the anti-inflammatory protein annexin A1 in cystic fibrosis knock-out mice and patients. Mol. Cell Proteomics 4, 1591-1601 (2005).

202. Haston, C.K., McKerlie, C., Newbigging, S., Corey, M., Rozmahel, R. \& Tsui, L.C. Detection of modifier loci influencing the lung phenotype of cystic fibrosis knockout mice. Mamm. Genome. 13, 605-613 (2002).

203. Salvatore, F., Scudiero, O. \& Castaldo, G. Genotype-phenotype correlation in cystic fibrosis: the role of modifier genes. Am. J. Med. Genet 111, 88-95 (2002).

204. Davidson, D.J., Webb, S., Teague, P., Govan, J.R. \& Dorin, J.R. Lung pathology in response to repeated exposure to Staphylococcus aureus in congenic residual function cystic fibrosis mice does not increase in response to decreased CFTR levels or increased bacterial load. Pathobiology 71, 152-158 (2004).

205. Stotland, P.K., Radzioch, D. \& Stevenson, M.M. Mouse models of chronic lung infection with Pseudomonas aeruginosa: models for the study of cystic fibrosis. Pediatr. Pulmonol. 30, 413-424 (2000).

206. Durie, P.R., Kent, G., Phillips, M.J. \& Ackerley, C.A. Characteristic multiorgan pathology of cystic fibrosis in a long-living cystic fibrosis transmembrane regulator knockout murine model. Am. J. Pathol. 164, 1481-1493 (2004). 
207. Burkhardt, A. Alveolitis and collapse in the pathogenesis of pulmonary fibrosis. Am. Rev. Respir. Dis. 140, 513-524 (1989).

208. Carver, J.R. et al. American Society of Clinical Oncology clinical evidence review on the ongoing care of adult cancer survivors: cardiac and pulmonary late effects. J. Clin. Oncol. 25, 3991-4008 (2007).

209. Vagane, R., Bruland, O.S., Fossa, S.D. \& Olsen, D.R. Radiological and functional assessment of radiation-induced pulmonary damage following breast irradiation. Acta. Oncol. 47, 248-254 (2008).

210. Ghafoori, P., Marks, L.B., Vujaskovic, Z. \& Kelsey, C.R. Radiationinduced lung injury. Assessment, management, and prevention. Oncology (Williston Park) 22, 37-47; discussion 52-3 (2008).

211. Beinert, T. et al. Oxidant-induced lung injury in anticancer therapy. Eur. J. Med. Res. 4, 43-53 (1999).

212. Rodningen, O.K., Borresen-Dale, A.L., Alsner, J., Hastie, T. \& Overgaard, $J$. Radiation-induced gene expression in human subcutaneous fibroblasts is predictive of radiation-induced fibrosis. Radiother Oncol. 86, 314-320 (2008).

213. Lemay, A.M. \& Haston, C.K. Radiation-induced lung response of AcB/ BcA recombinant congenic mice. Radiat Res. 170, 299-306 (2008).

214. Johnston, C.J., Williams, J.P., Elder, A., Hernady, E. \& Finkelstein, J.N. Inflammatory cell recruitment following thoracic irradiation. Exp. Lung Res. 30, 369-382 (2004).

215. Westermann, W., Schobl, R., Rieber, E.P. \& Frank, K.H. Th2 cells as effectors in postirradiation pulmonary damage preceding fibrosis in the rat. Int. J. Radiat. Biol. 75, 629-638 (1999).

216. Barthelemy-Brichant, N. et al. Increased IL-6 and TGF-beta1 concentrations in bronchoalveolar lavage fluid associated with thoracic radiotherapy. Int. J. Radiat. Oncol. Biol. Phys. 58, 758-767 (2004).

217. Hill, R.P. Radiation effects on the respiratory system. BJR Suppl. 27, 75-81 (2005).

218. Matej, R., Housa, D., Pouckova, P., Zadinova, M. \& Olejar, T. Radiationinduced production of PAR-1 and TGF-beta 1 mRNA in lung of C57BI6 and $\mathrm{C} 3 \mathrm{H}$ murine strains and influence of pharmacoprophylaxis by ACE inhibitors. Pathol. Res. Pract. 203, 107-114 (2007).

219. Molteni, A. et al. Effect of an angiotensin II receptor blocker and two angiotensin converting enzyme inhibitors on transforming growth factorbeta (TGF-beta) and alpha-actomyosin (alpha SMA), important mediators of radiation-induced pneumopathy and lung fibrosis. Curr. Pharm. Des. 13, 1307-1316 (2007).

220. Yang, K. et al. Matrix-Metallo-Proteinases and their tissue inhibitors in radiation-induced lung injury. Int. J. Radiat. Biol. 83, 665-676 (2007).

221. Johnston, C.J., Williams, J.P., Okunieff, P. \& Finkelstein, J.N. Radiationinduced pulmonary fibrosis: examination of chemokine and chemokine receptor families. Radiat. Res. 157, 256-265 (2002).

222. Haase, M.G., Klawitter, A., Geyer, P. \& Baretton, G.B. Expression of the immunomodulator IL-10 in type I pneumocytes of the rat: alterations of IL-10 expression in radiation-induced lung damage. J. Histochem Cytochem. 55, 1167-1172 (2007).

223. Sharplin, J. \& Franko, A.J. A quantitative histological study of straindependent differences in the effects of irradiation on mouse lung during the intermediate and late phases. Radiat Res. 119, 15-31 (1989).

224. Giotopoulos, G. et al. The late radiotherapy normal tissue injury phenotypes of telangiectasia, fibrosis and atrophy in breast cancer patients have distinct genotype-dependent causes. Br. J. Cancer 96, 1001-1007 (2007).

225. Abid, S.H., Malhotra, V. \& Perry, M.C. Radiation-induced and chemotherapy-induced pulmonary injury. Curr. Opin. Oncol. 13, 242-248 (2001).

226. Sleijfer, S. Bleomycin-induced pneumonitis. Chest 120, 617-624 (2001).

227. Umezawa, H., Ishizuka, M., Maeda, K. \& Takeuchi, T. Studies on bleomycin. Cancer 20, 891-895 (1967).

228. Umezawa, H. Chemistry and mechanism of action of bleomycin. Fed. Proc. 33, 2296-2302 (1974).

229. Van Barneveld, P.W. et al. Predictive factors for bleomycin-induced pneumonitis. Am. Rev. Respir. Dis. 130, 1078-1081 (1984).

230. Onuma, T., Holland, J.F., Masuda, H., Waligunda, J.A. \& Goldberg, G.A. Microbiological assay of bleomycin: inactivation, tissue distribution, and clearance. Cancer 33, 1230-1238 (1974).

231. Doelman, C.J. \& Bast, A. Oxygen radicals in lung pathology. Free Radic. Biol. Med. 9, 381-400 (1990).
232. Burger, R.M., Peisach, J. \& Horwitz, S.B. Activated bleomycin. A transient complex of drug, iron, and oxygen that degrades DNA. J. Biol. Chem. 256, 11636-11644 (1981).

233. Adamson, I.Y. \& Bowden, D.H. The pathogenesis of bloemycin-induced pulmonary fibrosis in mice. Am. J. Pathol. 77, 185-197 (1974).

234. Piguet, P.F., Rosen, H., Vesin, C. \& Grau, G.E. Effective treatment of the pulmonary fibrosis elicited in mice by bleomycin or silica with anti-CD-11 antibodies. Am. Rev. Respir. Dis. 147, 435-441 (1993).

235. Piguet, P.F., Collart, M.A., Grau, G.E., Kapanci, Y. \& Vassalli, P. Tumor necrosis factor/cachectin plays a key role in bleomycin-induced pneumopathy and fibrosis. J. Exp. Med. 170, 655-663 (1989).

236. Scheule, R.K., Perkins, R.C., Hamilton, R. \& Holian, A. Bleomycin stimulation of cytokine secretion by the human alveolar macrophage. Am. J. Physiol. 262 (4 Part 1), L386-L391 (1992).

237. Smith, R.E., Strieter, R.M., Phan, S.H., Lukacs, N. \& Kunkel, S.L. TNF and IL-6 mediate MIP-1alpha expression in bleomycin-induced lung injury. J. Leukoc. Biol. 64, 528-536 (1998).

238. Santana, A., Saxena, B., Noble, N.A., Gold, L.I. \& Marshall, B.C. Increased expression of transforming growth factor beta isoforms (beta 1, beta 2, beta 3) in bleomycin-induced pulmonary fibrosis. Am. J. Respir. Cell Mol. Biol. 13, 34-44 (1995).

239. Zhang, K., Flanders, K.C. \& Phan, S.H. Cellular localization of transforming growth factor-beta expression in bleomycin-induced pulmonary fibrosis. Am. J. Pathol. 147, 352-361 (1995).

240. Hagimoto, N., Kuwano, K., Nomoto, Y., Kunitake, R. \& Hara, N. Apoptosis and expression of Fas/Fas ligand mRNA in bleomycininduced pulmonary fibrosis in mice. Am. J. Respir. Cell Mol. Biol. 16, 91-101 (1997).

241. Giri, S.N., Hyde, D.M. \& Hollinger, M.A. Effect of antibody to transforming growth factor beta on bleomycin induced accumulation of lung collagen in mice. Thorax 48, 959-966 (1993).

242. Piguet, P.F., Vesin, C., Grau, G.E. \& Thompson, R.C. Interleukin 1 receptor antagonist (IL-1ra) prevents or cures pulmonary fibrosis elicited in mice by bleomycin or silica. Cytokine 5, 57-61 (1993).

243. Hao, H., Cohen, D.A., Jennings, C.D., Bryson, J.S. \& Kaplan, A.M. Bleomycin-induced pulmonary fibrosis is independent of eosinophils. J. Leukoc. Biol. 68, 515-521 (2000).

244. Izbicki, G. \& Breuer, R. IL-4 is not a key profibrotic cytokine in bleomycininduced lung fibrosis model. J. Immunol. 171, 2767-2768; author reply 8 (2003).

245. McKay, D.L. Jr, Fuqua, F. \& Weinberg, A.G. Balanitis xerotica obliterans in children. J. Urol. 114, 773-775 (1975).

246. Segel, M.J. et al. Role of interferon-gamma in the evolution of murine bleomycin lung fibrosis. Am. J. Physiol. 285, L1255-L1262 (2003).

247. Chen, E.S., Greenlee, B.M., Wills-Karp, M. \& Moller, D.R. Attenuation of lung inflammation and fibrosis in interferon-gamma-deficient mice after intratracheal bleomycin. Am. J. Respir. Cell Mol. Biol. 24, 545-555 (2001).

248. Sakamoto, H., Zhao, L.H., Jain, F. \& Kradin, R. IL-12p40(-/-) mice treated with intratracheal bleomycin exhibit decreased pulmonary inflammation and increased fibrosis. Exp. Mol. Pathol. 72, 1-9 (2002).

249. Moseley, P.L., Hemken, C. \& Hunninghake, G.W. Augmentation of fibroblast proliferation by bleomycin. J. Clin. Invest. 78, 1150-1154 (1986).

250. Phan, S.H., Gharaee-Kermani, M., Wolber, F. \& Ryan, U.S. Stimulation of rat endothelial cell transforming growth factor-beta production by bleomycin. J. Clin. Invest. 87, 148-154 (1991).

251. Eder, W., Ege, M.J. \& von Mutius, E. The asthma epidemic. N. Engl. J. Med. 355, 2226-2235 (2006).

252. Martinez, F.D. Gene-environment interactions in asthma and allergies: a new paradigm to understand disease causation. Immunol. Allergy Clin. North Am. 25, 709-721 (2005).

253. Cohn, L., Elias, J.A. \& Chupp, G.L. Asthma: mechanisms of disease persistence and progression. Annu. Rev. Immunol. 22, 789-815 (2004).

254. Boulet, L.P. \& Sterk, P.J. Airway remodelling: the future. Eur. Respir. J. 30, 831-834 (2007).

255. Broide, D.H. Immunologic and inflammatory mechanisms that drive asthma progression to remodeling. J. Allergy Clin. Immunol. 121, 560-570; quiz 71-2 (2008).

256. Huang, J., Olivenstein, R., Taha, R., Hamid, Q. \& Ludwig, M. Enhanced proteoglycan deposition in the airway wall of atopic asthmatics. Am. J. Resp. Crit. Care Med. 160, 725-729 (1999). 
257. Ward, C. et al. Airway inflammation, basement membrane thickening and bronchial hyperresponsiveness in asthma. Thorax 57, 309-316 (2002).

258. Angkasekwinai, P. et al. Interleukin 25 promotes the initiation of proallergic type 2 responses. J. Exp. Med. 204, 1509-1517 (2007).

259. Owyang, A.M. et al. Interleukin 25 regulates type 2 cytokine-dependent immunity and limits chronic inflammation in the gastrointestinal tract. J. Exp. Med. 203, 843-849 (2006).

260. Sharkhuu, T. et al. Mechanism of interleukin-25 (IL-17E)-induced pulmonary inflammation and airways hyper-reactivity. Clin. Exp. Allergy 36, 1575-1583 (2006).

261. Min, B. et al. Basophils produce IL-4 and accumulate in tissues after infection with a Th2-inducing parasite. J. Exp. Med. 200, 507-517 (2004).

262. Voehringer, D., Shinkai, K. \& Locksley, R.M. Type 2 immunity reflects orchestrated recruitment of cells committed to IL-4 production. Immunity 20, 267-277 (2004).

263. Webb, D.C., Cai, Y., Matthaei, K.I. \& Foster, P.S. Comparative roles of IL4, IL-13, and IL-4Ralpha in dendritic cell maturation and CD4+ Th2 cell function. J. Immunol. 178, 219-227 (2007).

264. Hauber, H.P., Bergeron, C. \& Hamid, Q. IL-9 in allergic inflammation. Int. Arch. Allergy Immunol. 134, 79-87 (2004).

265. Woodman, L. et al. Mast cells promote airway smooth muscle cell differentiation via autocrine up-regulation of TGF-beta1. J. Immunol. 181, 5001-5007 (2008).

266. Coutts, A. et al. Release of biologically active TGF-beta from airway smooth muscle cells induces autocrine synthesis of collagen. $A m$. J. Physiol. 280, L999-L1008 (2001).

267. Balzar, S. et al. Increased TGF-beta2 in severe asthma with eosinophilia. J. Allergy Clin. Immunol. 115, 110-117 (2005).

268. Batra, V. et al. Bronchoalveolar lavage fluid concentrations of transforming growth factor (TGF)-beta1, TGF-beta2, interleukin (IL)-4 and IL-13 after segmental allergen challenge and their effects on alphasmooth muscle actin and collagen III synthesis by primary human lung fibroblasts. Clin. Exp. Allergy 34, 437-444 (2004).

269. Levi-Schaffer, F. et al. Human eosinophils regulate human lung- and skin-derived fibroblast properties in vitro: a role for transforming growth factor beta (TGF-beta). Proc. Natl. Acad. Sci. USA. 96, 9660-9665 (1999).

270. Sagara, H. et al. Activation of TGF-beta/Smad2 signaling is associated with airway remodeling in asthma. J. Allergy Clin. Immunol. 110, 249-254 (2002).

271. Flood-Page, P. et al. Anti-IL-5 treatment reduces deposition of ECM proteins in the bronchial subepithelial basement membrane of mild atopic asthmatics. J. Clin. Invest. 112, 1029-1036 (2003).

272. Kang, H.R., Cho, S.J., Lee, C.G., Homer, R.J. \& Elias, J.A. Transforming growth factor (TGF)-beta1 stimulates pulmonary fibrosis and inflammation via a Bax-dependent, bid-activated pathway that involves matrix metalloproteinase-12. J. Biol. Chem. 282, 7723-7732 (2007).

273. Phipps, S., Flood-Page, P., Menzies-Gow, A., Ong, Y.E. \& Kay, A.B. Intravenous anti-IL-5 monoclonal antibody reduces eosinophils and tenascin deposition in allergen-challenged human atopic skin. J. Invest Dermatol. 122, 1406-1412 (2004).

274. Menzies-Gow, A. et al. Anti-IL-5 (mepolizumab) therapy induces bone marrow eosinophil maturational arrest and decreases eosinophil progenitors in the bronchial mucosa of atopic asthmatics. J. Allergy Clin. Immunol. 111, 714-719 (2003).

275. Flood-Page, P.T., Menzies-Gow, A.N., Kay, A.B. \& Robinson, D.S. Eosinophil's role remains uncertain as anti-interleukin- 5 only partially depletes numbers in asthmatic airway. Am. J. Resp. Crit. Care Med. 167, 199-204 (2003).

276. O'Byrne, P.M. The demise of anti IL-5 for asthma, or not. Am. J. Resp. Crit. Care Med. 176, 1059-1060 (2007).

277. Cho, J.Y. et al. Inhibition of airway remodeling in IL-5-deficient mice. J. Clin. Invest. 113, 551-560 (2004).

278. Humbles, A.A. et al. A critical role for eosinophils in allergic airways remodeling. Science 305, 1776-1779 (2004).

279. Lee, J.J. et al. Defining a link with asthma in mice congenitally deficient in eosinophils. Science 305, 1773-1776 (2004).

280. McMillan, S.J., Xanthou, G. \& Lloyd, C.M. Manipulation of allergeninduced airway remodeling by treatment with anti-TGF-beta antibody: effect on the Smad signaling pathway. J. Immunol. 174, 5774-5780 (2005).
281. Le, A.V., Cho, J.Y., Miller, M., McElwain, S., Golgotiu, K. \& Broide, D.H. Inhibition of allergen-induced airway remodeling in Smad 3-deficient mice. J. Immunol. 178, 7310-7316 (2007).

282. Kondo, M. et al. Elimination of IL-13 reverses established goblet cell metaplasia into ciliated epithelia in airway epithelial cell culture. Allergol. Int. 55, 329-336 (2006).

283. Fanta, C.H. Clinical aspects of mucus and mucous plugging in asthma. J. Asthma. 22, 295-301 (1985).

284. Ramalingam, T.R. et al. Unique functions of the type II interleukin 4 receptor identified in mice lacking the interleukin 13 receptor alpha1 chain. Nat. Immunol. 9, 25-33 (2008).

285. Allahverdian, S., Harada, N., Singhera, G.K., Knight, D.A. \& Dorscheid, D.R. Secretion of IL-13 by airway epithelial cells enhances epithelial repair via HB-EGF. Am. J. Respir. Cell Mol. Biol. 38, 153-160 (2008).

286. Booth, B.W., Adler, K.B., Bonner, J.C., Tournier, F. \& Martin, L.D. Interleukin-13 induces proliferation of human airway epithelial cells in vitro via a mechanism mediated by transforming growth factor-alpha Am. J. Respir. Cell Mol. Biol. 25, 739-743 (2001).

287. Saito, A., Okazaki, H., Sugawara, I., Yamamoto, K. \& Takizawa, H. Potential action of IL-4 and IL-13 as fibrogenic factors on lung fibroblasts in vitro. Int. Arch. Allergy Immunol. 132, 168-176 (2003).

288. Richter, A. et al. The contribution of interleukin (IL)-4 and IL-13 to the epithelial-mesenchymal trophic unit in asthma. Am. J. Respir. Cell Mol. Biol. 25, 385-391 (2001).

289. Chiba, Y., Nakazawa, S., Todoroki, M., Shinozaki, K., Sakai, H. \& Misawa, M. Interleukin-13 Augments Bronchial Smooth Muscle Contractility with an Upregulation of RhoA Protein. Am. J. Respir. Cell Mol. Biol. (2008). (E-pub ahead of print)

290. Wen, F.Q. et al. Interleukin-4- and interleukin-13-enhanced transforming growth factor-beta2 production in cultured human bronchial epithelial cells is attenuated by interferon-gamma. Am. J. Respir. Cell Mol. Biol. 26, 484-490 (2002).

291. Zhou, X. et al. Interleukin-13 augments transforming growth factorbeta1-induced tissue inhibitor of metalloproteinase-1 expression in primary human airway fibroblasts. Am. J. Physiol. Cell Physiol. 288, C435-C442 (2005).

292. Zhou, X. et al. Mechanisms of tissue inhibitor of metalloproteinase 1 augmentation by IL-13 on TGF-beta 1-stimulated primary human fibroblasts. J. Allergy Clin. Immunol. 119, 1388-1397 (2007).

293. Paris, C. et al. Factors associated with early-stage pulmonary fibrosis as determined by high-resolution computed tomography among persons occupationally exposed to asbestos. Scand J. Work Environ. Health $\mathbf{3 0}$, 206-214 (2004).

294. Schenker, M. Exposures and health effects from inorganic agricultural dusts. Environ. Health Perspect 108 (Suppl 4), 661-664 (2000).

295. Von Essen, S., Robbins, R.A., Thompson, A.B. \& Rennard, S.I. Organic dust toxic syndrome: an acute febrile reaction to organic dust exposure distinct from hypersensitivity pneumonitis. J. Toxicol. Clin. Toxicol. 28, 389-420 (1990).

296. Buerke, U., Schneider, J., Rosler, J. \& Woitowitz, H.J. Interstitial pulmonary fibrosis after severe exposure to welding fumes. Am. J. Ind. Med. 41, 259-268 (2002).

297. Che, D.Y., Liu, S.C. \& Huang, X.Z. Pathogenesis of extrinsic allergic alveolitis and pulmonary fibrosis induced by streptomyces thermohygroscopicus. Chin. Med. J. (Engl.) 102, 563-567 (1989).

298. Cormier, Y., Brown, M., Worthy, S., Racine, G. \& Muller, N.L. Highresolution computed tomographic characteristics in acute farmer's lung and in its follow-up. Eur. Respir. J. 16, 56-60 (2000).

299. Lalancette, M. et al. Farmer's lung. Long-term outcome and lack of predictive value of bronchoalveolar lavage fibrosing factors. Am. Rev. Respir. Dis. 148, 216-221 (1993).

300. Toubas, D., Prevost, A., Deschamps, F. \& Pinon, J.M. Extrinsic allergic alveolitis of occupational origin]. Presse Med. 24, 1391-1396 (1995).

301. Hillerdal, G., Nou, E., Osterman, K. \& Schmekel, B. Sarcoidosis: epidemiology and prognosis. A 15-year European study. Am. Rev. Respir. Dis. 130, 29-32 (1984).

302. Nunes, H., Bouvry, D., Soler, P. \& Valeyre, D. Sarcoidosis. Orphanet J. Rare Dis. 2, 46 (2007).

303. Gaede, K.I., Mamat, U. \& Muller-Quernheim, J. Differential gene expression pattern in alveolar macrophages of patients with sarcoidosis and tuberculosis. J. Mol. Med. 82, 206-210 (2004). 
304. Abehsera, M., Valeyre, D., Grenier, P., Jaillet, H., Battesti, J.P. \& Brauner, M.W. Sarcoidosis with pulmonary fibrosis: CT patterns and correlation with pulmonary function. AJRAm. J. Roentgenol. 174, 1751-1757 (2000).

305. Roman, J., Jeon, Y.J., Gal, A. \& Perez, R.L. Distribution of extracellular matrices, matrix receptors, and transforming growth factor-beta 1 in human and experimental lung granulomatous inflammation. Am. J. Med. Sci. 309, 124-133 (1995)

306. Hutyrova, B. et al. Interleukin-1 gene cluster polymorphisms in sarcoidosis and idiopathic pulmonary fibrosis. Am. J. Resp. Crit. Care Med. 165, 148-151 (2002)

307. Muller-Quernheim, J. Sarcoidosis: immunopathogenetic concepts and their clinical application. Eur. Respir. J. 12, 716-738 (1998).

308. Rottoli, P. et al. Cytokine profile and proteome analysis in bronchoalveolar lavage of patients with sarcoidosis, pulmonary fibrosis associated with systemic sclerosis and idiopathic pulmonary fibrosis. Proteomics 5, 1423-1430 (2005).

309. Ziegenhagen, M.W., Schrum, S., Zissel, G., Zipfel, P.F., Schlaak, M. \& Muller-Quernheim, J. Increased expression of proinflammatory chemokines in bronchoalveolar lavage cells of patients with progressing idiopathic pulmonary fibrosis and sarcoidosis. J. Investig Med. 46, 223-231 (1998).

310. Iida, K., Kadota, J., Kawakami, K., Matsubara, Y., Shirai, R. \& Kohno, S. Analysis of T cell subsets and beta chemokines in patients with pulmonary sarcoidosis. Thorax 52, 431-437 (1997).

311. Limper, A.H., Colby, T.V., Sanders, M.S., Asakura, S., Roche, P.C. \& DeRemee, R.A. Immunohistochemical localization of transforming growth factor-beta 1 in the nonnecrotizing granulomas of pulmonary sarcoidosis. Am. J. Resp. Crit. Care Med. 149, 197-204 (1994).

312. Marshall, B.G., Wangoo, A., Cook, H.T. \& Shaw, R.J. Increased inflammatory cytokines and new collagen formation in cutaneous tuberculosis and sarcoidosis. Thorax 51, 1253-1261 (1996).

313. Salez, F., Gosset, P., Copin, M.C., Lamblin Degros, C., Tonnel, A.B. \& Wallaert, B. Transforming growth factor-beta1 in sarcoidosis. Eur. Respir. J. 12, 913-919 (1998).

314. Kline, J.N., Schwartz, D.A., Monick, M.M., Floerchinger, C.S. \& Hunninghake, G.W. Relative release of interleukin-1 beta and interleukin1 receptor antagonist by alveolar macrophages. A study in asbestosinduced lung disease, sarcoidosis, and idiopathic pulmonary fibrosis. Chest 104, 47-53 (1993).

315. Baumgartner, K.B., Samet, J.M., Stidley, C.A., Colby, T.V. \& Waldron, J.A. Cigarette smoking: a risk factor for idiopathic pulmonary fibrosis. Am. J. Resp. Crit. Care Med. 155, 242-248 (1997).

316. Baumgartner, K.B. et al. Occupational and environmental risk factors for idiopathic pulmonary fibrosis: a multicenter case-control study. Collaborating Centers. Am. J. Epidemiol. 152, 307-315 (2000).

317. Iwai, K., Mori, T., Yamada, N., Yamaguchi, M. \& Hosoda, Y. Idiopathic pulmonary fibrosis. Epidemiologic approaches to occupational exposure. Am. J. Resp. Crit. Care Med. 150, 670-675 (1994).

318. Jakab, G.J. Sequential virus infections, bacterial superinfections, and fibrogenesis. Am. Rev. Respir. Dis. 142, 374-379 (1990).

319. Meliconi, R. et al. Incidence of hepatitis $C$ virus infection in Italian patients with idiopathic pulmonary fibrosis. Thorax 51, 315-317 (1996).

320. Pinsker, K.L., Schneyer, B., Becker, N. \& Kamholz, S.L. Usual interstitial pneumonia following Texas A2 influenza infection. Chest $\mathbf{8 0 , 1 2 3 - 1 2 6}$ (1981).

321. Qunn, L. et al. Hyperplastic epithelial foci in honeycomb lesions in idiopathic pulmonary fibrosis. Virchows Arch. 441, 271-278 (2002).

322. Bitterman, P.B., Rennard, S.I., Keogh, B.A., Wewers, M.D., Adelberg, S. \& Crystal, R.G. Familial idiopathic pulmonary fibrosis. Evidence of lung inflammation in unaffected family members. N. Engl. J. Med. 314, 1343-1347 (1986).

323. Verleden, G.M. et al. Genetic predisposition and pathogenetic mechanisms of interstitial lung diseases of unknown origin. Eur. Respir. J. Suppl. 32, 17s-29s (2001).

324. Gribbin, J., Hubbard, R.B., Le Jeune, I., Smith, C.J., West, J. \& Tata, L.J. Incidence and mortality of idiopathic pulmonary fibrosis and sarcoidosis in the UK. Thorax 61, 980-985 (2006).

325. American Thoracic Society. Idiopathic pulmonary fibrosis: diagnosis and treatment. International consensus statement. American Thoracic Society (ATS), and the European Respiratory Society (ERS). Am. J. Resp. Crit. Care Med. 161 (2 Part 1), 646-664 (2000).
326. Crystal, R.G. et al. Future research directions in idiopathic pulmonary fibrosis: summary of a National Heart, Lung, and Blood Institute working group. Am. J. Resp. Crit. Care Med. 166, 236-246 (2002).

327. Crystal, R.G., Bitterman, P.B., Rennard, S.I., Hance, A.J. \& Keogh, B.A. Interstitial lung diseases of unknown cause. Disorders characterized by chronic inflammation of the lower respiratory tract (first of two parts). N. Engl. J. Med. 310, 154-166 (1984).

328. Gauldie, J., Bonniaud, P., Sime, P., Ask, K. \& Kolb, M. TGF-beta, Smad3 and the process of progressive fibrosis. Biochem. Soc. Trans. 35 (Part 4), 661-664 (2007).

329. Flaherty, K.R. et al. Steroids in idiopathic pulmonary fibrosis: a prospective assessment of adverse reactions, response to therapy, and survival. Am. J. Med. 110, 278-282 (2001).

330. Khalil, N., O'Connor, R.N., Flanders, K.C. \& Unruh, H. TGF-beta 1, but not TGF-beta 2 or TGF-beta 3 , is differentially present in epithelial cells of advanced pulmonary fibrosis: an immunohistochemical study. Am. J. Respir. Cell Mol. Biol. 14, 131-138 (1996).

331. Xu, Y.D., Hua, J., Mui, A., O'Connor, R., Grotendorst, G. \& Khalil, N. Release of biologically active TGF-beta1 by alveolar epithelial cells results in pulmonary fibrosis. Am. J. Physiol. 285, L527-L539 (2003).

332. Pan, L.H., Ohtani, H., Yamauchi, K. \& Nagura, H. Co-expression of TNF alpha and IL-1 beta in human acute pulmonary fibrotic diseases: an immunohistochemical analysis. Pathol. Int. 46, 91-99 (1996).

333. Zhang, Y., Lee, T.C., Guillemin, B., Yu, M.C. \& Rom, W.N. Enhanced IL-1 beta and tumor necrosis factor-alpha release and messenger RNA expression in macrophages from idiopathic pulmonary fibrosis or after asbestos exposure. J. Immunol. 150, 4188-4196 (1993).

334. Antoniou, K.M. et al. Th1 cytokine pattern (IL-12 and IL-18) in bronchoalveolar lavage fluid (BALF) before and after treatment with interferon gamma-1b (IFN-gamma-1b) or colchicine in patients with idiopathic pulmonary fibrosis (IPF/UIP). Sarcoidosis Vasc. Diffuse Lung Dis. 21, 105-110 (2004).

335. Antoniades, H.N. et al. Platelet-derived growth factor in idiopathic pulmonary fibrosis. J. Clin. Invest. 86, 1055-1064 (1990).

336. Standiford, T.J. et al. Altered production and regulation of monocyte chemoattractant protein-1 from pulmonary fibroblasts isolated from patients with idiopathic pulmonary fibrosis. Chest 103 (2 Suppl), $121 \mathrm{~S}$ (1993).

337. Furuie, H., Yamasaki, H., Suga, M. \& Ando, M. Altered accessory cell function of alveolar macrophages: a possible mechanism for induction of Th2 secretory profile in idiopathic pulmonary fibrosis. Eur. Respir. J. 10, 787-794 (1997).

338. Jakubzick, C. et al. Augmented pulmonary IL-4 and IL-13 receptor subunit expression in idiopathic interstitial pneumonia. J. Clin. Pathol. 57, 477-486 (2004).

339. Hunninghake, G.W., Gadek, J.E., Lawley, T.J. \& Crystal, R.G. Mechanisms of neutrophil accumulation in the lungs of patients with idiopathic pulmonary fibrosis. J. Clin. Invest. 68, 259-269 (1981).

340. Baptista, A.L., Parra, E.R., Filho, J.V., Kairalla, R.A., de Carvalho, C.R. \& Capelozzi, V.L. Structural features of epithelial remodeling in usual interstitial pneumonia histologic pattern. Lung 184, 239-244( 2006).

341. Agusti, A.G., Roca, J., Gea, J., Wagner, P.D., Xaubet, A. \& RodriguezRoisin, R. Mechanisms of gas-exchange impairment in idiopathic pulmonary fibrosis. Am. Rev. Respir. Dis. 143, 219-225 (1991).

342. Holsti, M.A. et al. Regulation of postsurgical fibrosis by the programmed death-1 inhibitory pathway. J. Immunol. 172, 5774-5781 (2004).

343. Moore, K.W., de Waal Malefyt, R., Coffman, R.L. \& O'Garra, A. Interleukin-10 and the interleukin-10 receptor. Annu. Rev. Immunol. 19, 683-765 (2001).

344. Garantziotis, S. et al. Leukocyte-derived IL-10 reduces subepithelial fibrosis associated with chronically inhaled endotoxin. Am. J. Respir. Cell Mol. Biol. 35, 662-667 (2006).

345. Arai, T. et al. Introduction of the interleukin-10 gene into mice inhibited bleomycin-induced lung injury in vivo. Am. J. Physiol. 278, L914-L922 (2000).

346. Dosanjh, A.K., Elashoff, D. \& Robbins, R.C. The bronchoalveolar lavage fluid of cystic fibrosis lung transplant recipients demonstrates increased interleukin-8 and elastase and decreased IL-10. J. Interferon Cytokine Res. 18, 851-854 (1998).

347. Millar, A.B. IL-10: another therapeutic target in idiopathic pulmonary fibrosis? Thorax 61, 835-836 (2006). 
348. $\mathrm{Mu}, \mathrm{W}$. et al. IL-10 suppresses chemokines, inflammation, and fibrosis in a model of chronic renal disease. J. Am. Soc. Nephrol. 16, 3651-3660 (2005).

349. Wynn, T.A. et al. IL-10 regulates liver pathology in acute murine Schistosomiasis mansoni but is not required for immune downmodulation of chronic disease. J. Immunol. 160, 4473-4480 (1998).

350. Hoffmann, K.F., Cheever, A.W. \& Wynn, T.A. IL-10 and the dangers of immune polarization: excessive type 1 and type 2 cytokine responses induce distinct forms of lethal immunopathology in murine schistosomiasis. J. Immunol. 164, 6406-6416 (2000).

351. Wilson, M.S., Pesce, J.T., Ramalingam, T.R., Thompson, R.W., Cheever, A. \& Wynn, T.A. Suppression of murine allergic airway disease by IL-2: anti-IL-2 monoclonal antibody-induced regulatory T cells. J. Immunol. 181, 6942-6954 (2008).

352. Kasaian, M.T. \& Miller, D.K. IL-13 as a therapeutic target for respiratory disease. Biochem Pharmacol. 76, 147-155 (2008).

353. Zhu, Z. et al. IL-13-induced chemokine responses in the lung: role of CCR2 in the pathogenesis of IL-13-induced inflammation and remodeling. J. Immunol. 168, 2953-2962 (2002).

354. Bottinger, E.P. et al. The recombinant proregion of transforming growth factor beta1 (latency-associated peptide) inhibits active transforming growth factor beta1 in transgenic mice. Proc. Natl. Acad. Sci. USA. 93 5877-5882 (1996)

355. Rodriguez-Pena, A. et al. Up-regulation of endoglin, a TGF-beta-binding protein, in rats with experimental renal fibrosis induced by renal mass reduction. Nephrol. Dial. Transplant 16 (Suppl 1), 34-39 (2001).

356. Gurujeyalakshmi, G., Hollinger, M.A. \& Giri, S.N. Regulation of transforming growth factor-beta1 mRNA expression by taurine and niacin in the bleomycin hamster model of lung fibrosis. Am. J. Respir. Cell Mol. Biol. 18, 334-342 (1998).

357. Yang, K.L., Chang, W.T., Chuang, C.C., Hung, K.C. \& Li, E.I. Antagonizing TGF-beta induced liver fibrosis by a retinoic acid derivative through regulation of ROS and calcium influx. Biochem. Biophys. Res. Commun. 365, 484-489 (2008).

358. Cutroneo, K.R., White, S.L., Phan, S.H. \& Ehrlich, H.P. Therapies for bleomycin induced lung fibrosis through regulation of TGF-beta1 induced collagen gene expression. J. Cell Physiol. 211, 585-589 (2007).

359. Chiaramonte, M.G., Donaldson, D.D., Cheever, A.W. \&Wynn, T.A. An IL-13 inhibitor blocks the development of hepatic fibrosis during a T-helper type 2-dominated inflammatory response. J. Clin. Invest. 104, 777-785 (1999).

360. Fallon, P.G., Richardson, E.J., McKenzie, G.J. \& McKenzie, A.N Schistosome infection of transgenic mice defines distinct and contrasting pathogenic roles for $\mathrm{IL}-4$ and $\mathrm{IL}-13: \mathrm{IL}-13$ is a profibrotic agent. J. Immunol. 164, 2585-2591 (2000).

361. Zheng, T. et al. IL-13 receptor alpha2 selectively inhibits IL-13-induced responses in the murine lung. J. Immunol. 180, 522-529 (2008).

362. Wills-Karp, M. et al. Interleukin-13: central mediator of allergic asthma. Science 282, 2258-2261 (1998).

363. Mentink-Kane, M.M. \& Wynn, T.A. Opposing roles for IL-13 and IL-13 receptor alpha 2 in health and disease. Immunol. Rev. 202, 191-202 (2004)

364. Mentink-Kane, M.M. et al. IL-13 receptor alpha 2 down-modulates granulomatous inflammation and prolongs host survival in schistosomiasis. Proc. Natl. Acad. Sci. USA. 101, 586-590 (2004).

365. Mu, D. et al. The integrin alpha(v)beta8 mediates epithelial homeostasis through MT1-MMP-dependent activation of TGF-beta1. J. Cell Biol. 157, 493-507 (2002).

366. Maeda, S., Dean, D.D., Gomez, R., Schwartz, Z. \& Boyan, B.D. The first stage of transforming growth factor beta1 activation is release of the large latent complex from the extracellular matrix of growth plate chondrocytes by matrix vesicle stromelysin-1 (MMP-3). Calcif Tissue Int. 70, 54-65 (2002).

367. Alfranca, A. et al. PGE2 induces angiogenesis via MT1-MMP-mediated activation of the TGFbeta/Alk5 signaling pathway. Blood 112, 1120-1128 (2008).

368. Kim, H.S., Luo, L., Pflugfelder, S.C. \& Li, D.Q. Doxycycline inhibits TGF-beta1-induced MMP-9 via Smad and MAPK pathways in human corneal epithelial cells. Invest Ophthalmol Vis Sci. 46, 840-848 (2005).

369. Agren, M.S. Matrix metalloproteinases (MMPs) are required for reepithelialization of cutaneous wounds. Arch. Dermatol. Res. 291, 583-590 (1999)

370. Pourgholami, M.H. \& Morris, D.L. Inhibitors of vascular endothelial growth factor in cancer. Cardiovasc Hematol. Agents Med. Chem. 6, 343-347 (2008).

371. Yoshiji, H., Kuriyama, S. \& Fukui, H. Angiotensin-I-converting enzyme inhibitors may be an alternative anti-angiogenic strategy in the treatment of liver fibrosis and hepatocellular carcinoma. Possible role of vascular endothelial growth factor. Tumour Biol. 23, 348-356 (2002).

372. Bizzarri, C., Beccari, A.R., Bertini, R., Cavicchia, M.R., Giorgini, S. \& Allegretti, M. ELR+ CXC chemokines and their receptors (CXC chemokine receptor 1 and $\mathrm{CXC}$ chemokine receptor 2) as new therapeutic targets. Pharmacol Ther. 112, 139-149 (2006).

373. Jiang, D. et al. Regulation of pulmonary fibrosis by chemokine receptor CXCR3. J. Clin. Invest. 114, 291-299 (2004).

374. Pochetuhen, K., Luzina, I.G., Lockatell, V., Choi, J., Todd, N.W. \& Atamas, S.P. Complex regulation of pulmonary inflammation and fibrosis by CCL18. Am. J. Pathol. 171, 428-437 (2007). 